IZA DP No. 10364

Gender Differences in Willingness to Compete:

The Role of Culture and Institutions

Alison Booth

Elliott Fan

Xin Meng

Dandan Zhang

November 2016 


\title{
Gender Differences in Willingness to Compete: The Role of Culture and Institutions
}

\author{
Alison Booth \\ Australian National University and IZA \\ Elliott Fan \\ National Taiwan University \\ Xin Meng \\ Australian National University and IZA \\ Dandan Zhang \\ Peking University \\ Discussion Paper No. 10364 \\ November 2016 \\ IZA \\ P.O. Box 7240 \\ 53072 Bonn \\ Germany \\ Phone: +49-228-3894-0 \\ Fax: +49-228-3894-180 \\ E-mail: iza@iza.org
}

\begin{abstract}
Any opinions expressed here are those of the author(s) and not those of IZA. Research published in this series may include views on policy, but the institute itself takes no institutional policy positions. The IZA research network is committed to the IZA Guiding Principles of Research Integrity.

The Institute for the Study of Labor (IZA) in Bonn is a local and virtual international research center and a place of communication between science, politics and business. IZA is an independent nonprofit organization supported by Deutsche Post Foundation. The center is associated with the University of Bonn and offers a stimulating research environment through its international network, workshops and conferences, data service, project support, research visits and doctoral program. IZA engages in (i) original and internationally competitive research in all fields of labor economics, (ii) development of policy concepts, and (iii) dissemination of research results and concepts to the interested public.
\end{abstract}

IZA Discussion Papers often represent preliminary work and are circulated to encourage discussion. Citation of such a paper should account for its provisional character. A revised version may be available directly from the author. 


\section{ABSTRACT}

\section{Gender Differences in Willingness to Compete: The Role of Culture and Institutions*}

In the laboratory experiment reported in this paper we explore how evolving institutions and social norms, which we label 'culture', change individuals' preferences and behaviour in mainland China. From 1949 China experienced dramatic changes in its socio-economic institutions. These began with communist central planning and the establishment of new social norms, including the promotion of gender equality in place of the Confucian view of female 'inferiority'. Market-oriented reforms, begun in 1978, helped China achieve unprecedented economic growth and at the same time Marxist ideology was gradually replaced by the acceptance of individualistic free-market ideology. During this period, many old traditions crept back and as a consequence social norms gradually changed again. In our experiment we investigate gender differences in competitive choices across different birth cohorts of individuals who, during their crucial developmental-age, were exposed to one of the two regimes outlined above. In particular we investigate gender differences in competitive choices for different birth cohorts in Beijing using their counterparts in Taipei (subject to the same original Confucian traditions) to control for the general time trend. Our findings confirm: (i) that females in Beijing are significantly more likely to compete than females from Taipei; (ii) that Beijing females from the 1958 birth cohort are more competitive than their male counterparts as well as more competitive than later Beijing birth cohorts; and (iii) that for Taipei there are no statistically significant differences across cohort or gender in willingness to compete. In summary, our findings confirm that exposure to different institutions and social norms during the crucial developmental age changes individuals' behaviour. Our findings also provide further evidence that gender differences in economic preferences are not innately determined.

JEL Classification: C9, C91, C92, J16, P3, P5, D03

Keywords: gender, competitive choices, culture, behavioural economics

Corresponding author:

Xin Meng

Research School of Economics

College of Business and Economics

Australian National University

HW Arndt Building 25a

ACT 0200

Australia

E-mail: Xin.Meng@anu.edu.au

\footnotetext{
* We would like to thank James Jilu Zhang for excellent research assistance. We would also like to thank Anpeng Li who provided data extracted from "People's Daily" for Figure 1. Funding from the Australian Research Council, the College of Business and Economics at ANU, and National Taiwan University is gratefully acknowledged. Ethics approval for the experiment was obtained from the Ethics Committee of the Australian National University and that of National University of Taiwan.
} 


\section{Introduction}

Gender gaps in labour market outcomes can be observed in most societies regardless of their stage of development. Recent studies have linked such phenomena with gender behavioural difference in the willingness to compete (e.g., Gneezy et al., 2003; Gneezy and Rustichini, 2004; Niederle and Vesterlund, 2007). The question then arises as to what determines male and female differences in competitive inclination. Economists have not reached consensus over this issue. Many studies believed that this is due mainly to nature: women and men are built differently. For example, there is some evidence that the menstrual cycle and hormone level affects competition inclination (see, for example, Buser, 2012). Moreover, in some societies the gender gap in competition inclination is found to exist as early as the age of three years and to persist for many years to come (see, for example, Sutter and Gltzle-Rutzler, 2015).

Recently, though, further studies have provided evidence indicating that nurture affects individuals' competitive inclination. Gneezy et al. (2009) examined the issue as to whether the gender gap in competitiveness is due to nature or nurture by comparing gender gaps in competitiveness between a patriarchal society and a matrilineal society. They found that, while women in the patriarchal society are less competitively inclined than men, their counterparts in the matrilineal society are more competitive than men. Their study indicates that culture matters and that it is possible to nurture women to be more competitive. Booth and Nolen (2012) compare gender gaps in competitive behaviour between girls and boys aged 14 and 15 from single-sex and coeducational environments, and find robust differences between the competitive choices of girls from single-sex and coed schools. Moreover, girls from single-sex schools behave more like boys when randomly assigned to mixed-sex experimental groups. Their results suggest that observed gender differences in other studies might reflect social learning rather than inherent gender traits.

'Culture' is a collective term that encompasses ideas, values, customs, social norms and social behaviour. Culture is said to be formed in the long-term and persist for generations (Guiso et al., 2006; Hofstede and Hofstede, 2005; Alesina et al., 2013). Yet studies have found that institutions, social interactions and indoctrination can affect social norms, social preferences, beliefs, and behaviour (Manski, 2000; Tabellini, 2010; Alesina and Fuchs-Schundeln, 2007). Thus some aspects of 'culture' can be formed or changed in a relatively short period. If this is the case and if this part of 'culture' matters in 
nurturing women's competitive behaviour, then policy intervention may contribute to the further narrowing of gender gaps in labour market outcomes.

This paper aims to test whether or not gender gap in competitive inclination can be altered in a relatively short period (that is, over four decades) by changing social norms induced from institutional changes. Our regions of interest are mainland China and Taiwan, both of which descend from the same Confucian traditions, but whose experiences from 1949 onwards dramatically diverged. The subjects of our experiment are different birth cohorts of men and women who were exposed to different regimes during their crucial developmental-age, and we investigate gender differences in their competitive choices. To summarise, our conjecture is that the cohort exposed to the most extreme gender-equality propaganda would not only behave differently from other cohorts in mainland China, but also from their counterparts in a society with similar ethnic and Confucian roots but with a divergent history from 1949 - Taiwan.

From 1949 onwards, mainland China experienced a series of dramatic changes in its social and economic institutions. During the first thirty years (1949-1977) the ruling communist party - guided by Marxist ideology - implemented a centrally planned economy. Like most communist regimes, within a short period mainland China denounced old Chinese culture and established new social norms. Among them, gender equality was promoted to replace the traditional Confucian view that women are subordinate to men and that the woman should be "obedient, quiet, self-effacing, ignorant, and devoting herself only to the service of the family". During those years, especially during the Cultural Revolution (1966-1976), women's position in society was strongly promoted while Confucian ideology was vilified. A widely known political slogan in mainland China promoting women's status in the society was 'women hold up half of the sky'. In addition, to encourage women to participate in the labour market, propaganda was spread that a society should not tolerate people who can work but choose not to; those who did so were regarded as 'social parasites' (Meng, 2000; Yao and You, 2016). As a result of such promotion and indoctrination, women's labour force participation rate in mainland China was at similar level as their male counterparts (Croll, 1983) and the gender earnings gap was small (Meng and Kidd, 1997).

Market-oriented economic reforms began in 1978, and these helped China achieve unprecedented economic growth. At the same time, the Marxist ideology was gradually 
replaced by an acceptance of individualistic and free-market ideology. During this period, many old Chinese traditions managed to creep back and social norms have gradually changed once more. Consequently, available data show that urban women's labour-force participation rate dropped from $78 \%$ in 1988 to $57 \%$ in 2009. In the meantime, the gender earnings gap continued to widen (Zhang et al., 2008).

Such dramatic changes in institutions and social norms are highly likely to affect individuals who, during the crucial developmental age, were exposed to one of the two regimes (Alesina and Fuchs-Schundeln, 2007). In particular, with regard to the gender gap in competitive inclination, we expect that women who grew up during the communist regime would be more confident about themselves and hence have a stronger competitive inclination conditional on their level of competence, while women who grew up mainly during the post-reform regime may be less inclined to compete. At the same time there might be a countering force. As the economy progresses and education levels increase, the growing dominance of market factors may promote individually-based preferences and increase awareness of gender equality (Xu and Hamamura, 2014; Cai and Sedikides, 2012), and hence, increase women's competitive inclinations.

To examine whether or not the thirty years of communist indoctrination has changed women's behaviour, we conducted controlled laboratory experiments with birth cohorts of mainland Chinese subjects who spent their crucial developmental age under different regimes. To control for the potential counterforce - induced over time by more education and market domination and induced gender-equality awareness - we conducted the same laboratory experiments with Taiwanese subjects born in the same years. Taiwan is a region that was subject to the same Confucian traditions and that also went through significant economic growth. However, it has not been subject to the ideological transformation experienced by mainland China. Using the results from the Taiwan experiments to gauge the general effect of economic growth, we find that the mainland women who were subject to the communist regime during the crucial developmental age were more inclined to compete than their male counterparts. In contrast, for our other two cohorts - one that was partially subject to the communist regime and partially subject to the new regime, and the other that was fully subject to the new regime - we observe either the opposite pattern or else no gender difference. We also find that, controlling for competence level, mainland women are on average more competitive than their counterparts 
in Taiwan for every birth cohort, a finding that perhaps relates to the role-model effect from their indoctrinated parents (Fernandez et al., 2004).

Are our findings truly due to the influence of communist ideology? In the exit surveys, we asked participants to report, from a list of personal attributes, those that their parents and schools encouraged them to develop when they were young. A significant proportion of the older cohorts of mainland participants choose from these attributes 'gender equality' and 'being unselfish', whereas no cohort differences were found among the Taiwanese participants. We also explored responses to two questions asking respondents whether they support or disagree with the statements that government should implement policy to reduce income inequality and that governments should intervene in the economy as little as possible. Our oldest Mainland cohort is more likely to agree with the former statement and to disagree with the latter one. For the Taiwanese participants, no cohort difference is found.

Our design ruled out the possibility that women's lack of competitive inclination is due mainly to innate ability. The fact that, within the same large culture background, different cohorts of women exhibit a sharp difference in competitive inclination, suggest that institution and culture interact to affect individuals' behaviour. If culture is a selective outcome, previous studies using long-lasting cultural differences, such as matrilineal vs. patrilineal societies (see, for example, Gneezy et al., 2009; and Zhang, 2015), may not be able to identify clearly the nurture effect due to the potential that societies selected into different cultures. In our setting, however, the effect of nurture is clearly demonstrated.

Our research also adds to an increasing number of studies confirming that induced change in social norms do indeed affect individual preferences and behaviour. For example, Liu et al. (2014) investigate how Confucianism affects economic preferences of subjects in mainland China and Taiwan by priming their subjects - university students with Confucianism. The finding that Chinese and Taiwanese subjects responded very differently to this priming is interpreted as the result of different histories and experiences. Zhang (2015) compares the competitive behaviour of experimental subjects from three ethnic groups (the Han, the Yi, and the Mosuo (a polygamous and matrilineal group)) at a high school in south-west mainland China in 2009. The last two ethnicities, who are minorities in China, were said to be somewhat exempt from the communist Chinese reforms relative to their Han counterparts. The author finds no evidence of a gender gap in 
competitive inclination amongst the Han Chinese, but a large gap for the Yi. The Mosuo women were as competitively inclined as the Han Chinese. Like these studies we investigate the impact of different life-experiences on behavioural outcomes. But in contrast to these studies, in order to try to get a handle on behavioural differences resulting from varying levels of exposure to communist indoctrination, we directly recruit as subjects different birth cohorts. These different cohorts spent their formative years - in the case of mainland China - in the very different social-economic regimes sketched out above.

The remainder of this paper is structured as follows. The next section provides background information on social-economic changes that occurred in Mainland China and Taiwan in the past 70 years and how it affected gender roles in the two societies differentially. Section 3 introduces the experimental design, our sample, and summary statistics. Section 4 presents the main results while Section 5 examines whether the observed difference in gender gap in competitive inclination is indeed due to the communist propaganda. Section 6 concludes the paper.

\section{Background}

Women's position in mainland Chinese society changed dramatically over the course of the last seven decades. Traditionally, Chinese culture has a very strong gender bias. The Confucian view of women is that they are subordinates of men, they are weak, and are born to serve others (Croll, 1995). A virtuous woman should be "obedient, quiet, self-effacing, ignorant, and devoting herself only to the service of the family" (Tseng, 1992). In the period prior to the Second World War, women had limited freedom in the society. They had to obey their fathers and brothers before marriage, their marriages were arranged, and after marriage, they belonged to their husbands' family and had to obey their husband and mother-in-law's domination, in the event that they were widowed, they were required to obey their sons (Croll, 1983; Ma, 1995; Hinton, 1966; Zhang, 2015). The end of the Second World War saw the Communist Party (CCP) seize control from their predecessor - the Kuomintang Party (KP) - in mainland China, while the latter formed the government in Taiwan.

Since 1949 mainland China has been ruled by the CCP, which adopted communist ideology and aimed to change Chinese society according to this ideology. Gender equality 
was at the top of the agenda for social transformation, perhaps following the role-model of the Communist Party in then Soviet Union (Little, 2011). The State undertook a series of legal reforms to establish the equality of women in marriage and family, in education and election rights, and in land rights and the right to participate in the labour market (Niida, 1964; Croll, 1995). They organised women to redefine and to promote their economic, social and political interests (Croll, 1983; Mow et al., 2004). The New Marriage Law was introduced in 1950. This upheld the principles of free marriage, monogamy, equal rights for men and women, and the protection of the natural rights of women, and opposed the patriarchal marriage practices centred on the interests of husbands and males (Niida, 1964; Yao and You, 2016). All these new ideas were in direct contradiction to the social norm of Confucianism that had dominated China for thousands of years. To change views and social norms in a short period, the CCP used mass-media propaganda to popularize the new ideas. These included positive and negative campaigns. On the positive side, slogans such as "women can hold up half the sky", "men and women are equal", "working is glorious", and "make your own marriage decision" appeared on propaganda posters, newspapers, and government documents. On the negative side, it was widely believed that a society would not tolerate individuals who were able but chose not to work. Those choosing not to work would be regarded as "social parasites" (Meng, 2000). At the same time, Confucianism was denounced, especially during the Cultural Revolution period (see for example, (Lu, 2004)).

Figure 1 plots the density of the the key words of "women hold up half the sky" and "gender equality" that appeared in "People's Daily", the official CCP newspaper, over the past 67 years (the density is calculated using the number of times these key words appeared in articles published in "People's Daily" each year divided by the total number of articles appeared in the paper in that year). The figure shows that there were three peak periods: 1950-1955; 1970-1976; and 1995. The first peak occurred during the early days of the introduction of the New Marriage Law. The second was during the Cultural Revolution period, while the third, 1995, was the year the UN Fourth Women's Conference was held in Beijing. Of the three peaks, the Cultural Revolution period is the most intensive one.

Taiwan's population is mostly Han Chinese who were born on the mainland or have ancestors who were Han Chinese from the mainland. Taiwan shares the same language 
and has a similar initial culture as that of mainland China. One of the most important parts of this initial culture is Confucian values, beliefs, and ethics, which have been passed down in Taiwan from parents to children and from teachers to students (Liu et al., 2014). Unlike the mainland, Taiwan did not experience a revolutionary ideological change after the Second World War, and traditional cultural values remain as dominant. Nevertheless, as the economy developed and educational levels improved, the society became more aware of gender equality issues, and the extreme Confucian values regarding women's position in a society gradually evolved into a more modern view. As such, women's labour force participation rate has been increasing,and as a result of women's financial independence, women are challenging traditional gender roles both within families and in workplaces.

Figure 2 presents the male and female labour force participation rates by age and gender for the years of the early 1980s and early 2010s for non-agriculture workers in Mainland China and Taiwan. ${ }^{1}$ The figures show that labour force participation rate of mainland women was very high in the earlier days, but over the past 30 years it has dropped significantly, especially for prime-aged women. Thus, as the Chinese economy grew, women's labour force participation rate reduced. The opposite is true in Taiwan. Although Taiwanese women are, on average, less likely to participate in the labour market, as the Taiwanese economy grew over the past 30 years primary-age women's participation rate has been increasing. The different trends described in these figures are largely due to the institutional and cultural changes described in this section. If we assume that economic growth should have a general trend of increasing women's labour force participation, the fact that in mainland China women's labour force participation is reducing as the economy grows suggests that a strong counter-force exists. We argue that to a large extent this counter force is related to the institutional changes described above.

\footnotetext{
${ }^{1}$ For mainland China, we use the 1982 Population Census data for the early period, and the China Family Panel Survey (CFPS) for the most recent period. We use only the urban population to generate this figure. The 1982 census is the first year we have data available for mainland China. For the year near our experiment, e are unable to access unit record data from the 2010 Population Census. As an alternative we used the representative household survey data (CFPS), which are close to our experiment year. For Taiwan, we use the 1980 census data. Also due to the unavailability of the 2010 census data we use, instead, 2010-2015 data from Taiwan Household Income and Expenditure surveys, conducted by Directorate-General of Budget, Accounting, and Statistics Executive Yuan.
} 


\section{Experimental Design and the Data}

In this paper we investigate whether or not individuals exposed to different regimes and social norms about women's position in a society vary in their willingness to compete. To do this, we need to identify birth cohorts that were exposed to different regimes. Based on Figure 1, in the mainland the period with the most intensive propaganda on gender equality was that of the Cultural Revolution. We therefore chose, as our treatment group, individuals born in 1958 (aged 8 to 17 during the Cultural Revolution) and whose schooling years thus ovelapped with the Cultural Revolution. They are not too old to have lost their cognitive ability at the time of the experiment (aged 57 in 2015) but are old enough to have spent their crucial development age during the Cultural Revolution. We have two comparison cohorts: (1) individuals born in the year the Cultural Revolution began (1966) and who spent 3 of their early primary school years during the Cultural Revolution and the remainder of their schooling years in the economic reform era (1977 onwards); and (2) individuals born in 1977 who spent their entire life in the economic reform era. We aimed at sampling around 100 individuals in each birth cohort from Beijing, the capital city of the mainland China, and they are equally divided along the gender line. A similar number of Taiwanese subjects were recruited from Taipei, the capital city of Taiwan, and among the same cohorts, in the same gender divide.

To ensure that our subjects are roughly representative of the population at large, we obtained the gender-education-employment distribution within each birth cohort from a combination of National Bureau of Statistics Urban Household Survey (UHS) data 2009 and the one percent 2010 Population Census data for Beijing sample. For Taipei, we used the Manpower Survey 2010-2015. ${ }^{2}$ These distributions are then used as our sampling quota to recruit subjects. The recruitment was carried out by survey companies in Beijing and Taipei through Internet or telephone contacts from the survey companies' own subject pools. We also used social media (Facebook in Taipei and WeChat in Beijing) ourselves to supplement the survey companies' recruitment efforts. In Taipei, we further advertised in communities through neighbourhood magistrates, elected officials at the bottom administration divisions around Taipei city. The advertisement texts in Mandarin are consistent between the two cities. ${ }^{3}$ The original sample quota by cohort-gender-

\footnotetext{
${ }^{2}$ The reason we used different data sets for Beijing or the same survey data from multiple years for Taipei is to enlarge the sample sizes.

${ }^{3}$ see Appendix B for the translated English text
} 
education-employment cells and the final sample distribution among these cells for Beijing and Taipei are presented in Appendix A.4. They show that, by and large, our final samples are consistent with the original quota.

\subsection{Experiments}

We conducted a series of experiments with our sample subjects, including the following games: competition, trust, risk, and loss aversion. These are widely used in the experimental literature investigating economic preferences. Below, we discuss our experimental procedures and then describe in details the two games reported in this paper: competition and risk game. The precise form of these games is given in the Appendix C.

Our sample subjects were invited to come to one of several identical lecture rooms in either Peking University or National Taiwan University. The experiments were conducted in large lecture rooms, in which participants were seated separately with enough space in between to ensure no interference from each other. Participants were given a show-up fee of 75 yuan in Beijing, which is equivalent to around US\$12, and in Taipei it was T $\$ 510$ or approximately US $\$ 16 .{ }^{4}$ Participants were told that they had been selected to participate in an experiment and that, during the experiment, they would have the opportunity to earn some money and the exact amount they would earn depends on their own decision and their luck. All participants were given the option of not participating, both before and during the experimental sessions, but no one opted out. At the end of the experiment, one of the tasks was randomly chosen for payment.

The experiments in Beijing were conducted between 24 April and 23 May, 2015, while in Taipei they lasted from 25 July to 5 September, 2015. The sessions were conducted by two of the authors of this paper (Fan and Zhang for Taipei and Beijing, respectively) working with a team of 15 to 20 student research assistants from National Taiwan University and Peking University. The experiments were all conducted in Mandarin, using pen and paper to avoid the potential problem that our older cohort might not be computer literate. Each participant received hard copies of the instructions for each game immediately before the beginning of each game, and these instructions were then also read out loud to the group as a whole. There were opportunities to ask questions, and test

\footnotetext{
${ }^{4}$ The difference in payments between the two cities is due to the fact that the average earnings of Taipei is 1.5 times of that the average earnings in Beijing. Due to our budget constraint, we paid Taipei participants 1.33 times of their Beijing counterparts.
} 
questions were included in the answering sheets for each game to enable us to ascertain whether participants understood the instructions. ${ }^{5}$ Participants marked their answer to each test question and their decision for each game on paper form (the answering sheet), which was distributed to the participants after reading the instructions to them for each game. Below we discuss the competition game and risk game procedures, with details provided in the Appendix C.

The design of the competition game loosely follows that of Niederle and Vesterlund (2007). ${ }^{6}$ More specifically, three rounds of the game were conducted. The task in each round consisted of finishing, in five minutes, as many as possible additions of sets of five two-digit numbers. In the first round, individuals were paid based on piece-rate: each correct answer was compensated by 12 yuan in Beijing and $\mathrm{T} \$ 78$ in Taipei. The second round was a compulsory tournament in which each subject was randomly assigned an anonymous partner. Those completing the most correct answers were awarded, in Beijing and Taipei, 24 yuan and $\mathrm{T} \$ 156$ for each correct answer, respectively; whereas those who lost in the tournament received nothing. In the third round, subjects were asked to make a choice: either to be paid by piece-rate or tournament. The piece-rate payment is the same as for round 1 while that for tournament is the same for round 2. However, for this third round, the results of those who chose to compete were compared with the scores of their partners in round $2 .^{7}$

All sessions followed the same order of the three rounds described above. An advantage to conducting three rounds of the competition game is that we can use the results from the first two rounds (the mandatory piece rate and tournament) to control for individuals' competence as well as the their ability to sustain pressure (difference in performances between the first two rounds).

The risk game follows Gneezy and Potters (1997), and involves a series of lottery choices. Subjects need to choose, for each of the 11 choices, between receiving an amount with certainty (101 Yuan in Beijing and T\$662 in Taipei, which was approximately US\$15

\footnotetext{
${ }^{5}$ Most respondents answered the test questions correctly. 30 observations from Beijing sample and 14 observations from Taipei sample failed to answer the test questions for rounds 1 and 2 of competition game correctly. We experimented with including dummies for these observations in or excluding them from our regression analysis but our results were little affected (see Appendix Table A.5).

${ }^{6}$ Niederle and Vesterlund (2007) provided feedbacks to the subjects at the end of the each round of the competition game regarding their own performance. We did not do so in our setting.

${ }^{7}$ This is to ensure subjects' choice on whether to compete is not due to issues not relating to competition inclination, such as not wanting to impose negative externalities on others or strategic response to beliefs about other participants choices.
} 
and US $\$ 20$, respectively) or a lottery with a $50 \%$ chance of receiving a larger amount and a $50 \%$ chance of receiving nothing. The lottery-winning amount increases gradually from 135 yuan or $\mathrm{T} \$ 889$ in the first choice to 475 yuan or $\mathrm{T} \$ 2109$ in the 11 th choice. Riskloving subjects would choose the lottery over certainty even when the potential gaining amount is small, while risk-averse individuals would only choose the lottery over certainty when the potential gain from so doing becomes sufficiently large. The particular choice used for the payoff for this game depends on a random draw of a pinpong ball from a box with 11 numbered balls (from 1 to 11 ) by one of the participants at the end of the risk game. Once the choice is determined, another participants was randomly selected to toss a coin which determined the outcome for those who had chosen a lottery. ${ }^{8}$

\section{$3.2 \quad$ Exit Survey}

After completion of the games, all participants were asked to fill out an exit survey questionnaire. In addition to the general demographic details, labour market outcomes, and personality traits of the individuals and their family members, we also asked a series of questions designed to elicit information about the environment in which individuals were brought up. These included questions about the attributes encouraged by parents and by schools during that period. The attributes include being independent, hard-working, responsible, imaginative, being tolerance and respectful of others, trusting other people, giving and looking after those less fortunate; gender equality; thrift and saving money; determination and perseverance; religious faith; unselfishness; and competitiveness. In addition, a set of opinion questions regarding preferences for government intervention was included in the survey.

At the end of the exit survey, a simplified 10-minute Raven's Matrices Test was given to each participant to gauge their intellectual ability. The test is a widely accepted indicator of higher order general mental ability that does not rely on cultural context or prior experience. Originally designed to provide information about a subjects' ability using a non-verbal setting uncontaminated by linguistic background, its results have been shown to be consistent across cultures and over time (Raven, 2000).

\footnotetext{
${ }^{8}$ However, as we played 3 games and the competition game with three different rounds in each session, only one of the five game/round was used for the actual payoff. Which particular game/round was used for final payoff in each session was determined randomly by drawing balls with number 1 to 5 from a box.
} 


\subsection{Summary Statistics}

Table 1 reports the summary statistics of the subjects' characteristics by region, gender, and cohort. Our sample is not entirely balanced across cohorts and genders. In particular, the number of observation for the 1958 male cohort in Beijing is small relative to the other cohorts-gender cells in Beijing or Taipei (see the top panel of Table 1).

In terms of years of schooling, the gender differences across the cohorts are similar in Beijing and Taipei: while there is a visible female disadvantage for the 1958 cohort, it disappears for the later cohorts. Years of schooling are calculated based on the highest level of education reported by individual subjects and the normal number of years of education for each level in mainland and Taiwan to obtain a comparable measure across the two cities. However, during the Cultural Revolution most mainland urban schools were closed for between 3 and 7 years. ${ }^{9}$ Many birth cohorts whose education was interrupted during that period were given certificates for that level of education level they were supposed to have completed despite the fact that they did not receive that education. After the period of school closure, although schools were reopened and children at schools were educated, the quality of education during the Cultural Revolution was very questionable (Deng and Treiman, 1997; Meng and Gregory, 2002). Within our sample, the Beijing cohort born in 1958 had their education interrupted for a total of 6 years during the Cultural Revolution. The 1966 birth cohort was also affected for 3 years in their early primary school education due to the lower quality of education in those years. These interruptions may be the reason that, when comparing Raven's test scores, on average, mainland Chinese individuals were doing worse and in particular, the 1958 cohort in Beijing did the worst. This pattern will appear again when we discuss subjects' performance in competition games.

We also report summary statistics for mother's education, number of siblings, and marital status variables. All the variables exhibit large differences among cohorts from Beijing and Taipei. On average Beijing cohorts have higher values for "mother's education" for all cohorts. Taipei cohorts have significantly more siblings than their Beijing counterparts, while the Beijing cohorts are more likely to be married than single relative to their Taipei counterparts. These may all be related to policy and social norm differences.

\footnotetext{
${ }^{9}$ All levels of schools were closed in urban areas in mainland China between 1966 and 1969. Then, primary and junior high school were reopened in 1968-69 academic year. However, senior high school did not reopen for recruitment until 1972, while merit-based university entrance did not resume until after the Cultural Revolution in 1977 (Deng and Treiman, 1997; Meng and Gregory, 2002)
} 
Table 2 presents the summary statistics of the competition game. The first panel shows the proportion of people choosing to compete in the third round in each cohortgender cell for Beijing and Taipei separately. The last two columns in this panel report gender gaps in competitive inclination and t-ratios for the differences. The results indicate that, for the Beijing subjects, the 1958 women are statistically significantly more likely to choose to compete than their male counterparts, while women in the 1966 cohort are less likely to choose to compete. No statistically significant difference is observed for the 1977 cohort. For our Taipei sample, however, no gender difference in competition inclination is observed for any cohort.

The middle panel of Table 2 reports the average number of correct answers achieved in the first round (piece-rate) of the competition game by each cohort-gender cell. The last two columns of the panel show the gender difference in performance for Beijing and Taipei separately. The bottom panel shows the same data for the second round (compulsory tournament) of the competition game.

Figures 3 and 4 present the cumulative density functions for these two rounds by each gender, cohort, and region as well. These data confirm that, on average, the Beijing cohorts performed badly relative to their Taipei counterparts, especially the 1958 cohort, whose education interruption during the Cultural Revolution is clearly revealed from these performance results. Table 2 shows that males and females in the 1958 Beijing cohort completed, respectively, 5.2 and 7.3 correct answers in the first round and 7.0 and 8.2 in the second round. Their completed correct answers in the first round are only $44 \%$ and $64 \%$ of the correct answers completed by their Taipei counterparts, respectively. While the 1966 Beijing male and female cohorts are doing better than their 1958 counterparts, they still only completed $82 \%$ and $77 \%$ of the correct answers supplied by their Taipei counterparts. The results from the bottom two panels of Table 2, as well as from the cumulative density plots, indicate that the simple differences in competitive inclination without controlling for differences in performance may not be comparable across cohorts and across Beijing and Taipei. We control for differences in performance in our preferred specifications in the following section. 


\section{Gender gap in competitive inclination}

Niederle and Vesterlund (2007) discussed in detail the factors that may affect gender differences in competitive inclination in addition to preference for competition. In particular, they discussed gender differences in overconfidence, risk aversion, and feedback aversion. In addition, men and women may differ in performance under pressure. To examine whether gender difference in competitive inclination vary across different birth cohorts, we estimate the following regression:

$$
\text { Comp }_{i j}=\alpha+\beta_{j} \text { Coh }_{i j}+\kappa \text { Male }_{i j}+\rho_{j} \text { Coh }_{i j} * \text { Male }_{i j}+\theta W_{i j}+\gamma X_{i j}+\varepsilon_{i j},
$$

where the subscripts $i$ and $j$ indicate the individual and the birth cohort, respectively $(j=$ 1966 or 1977); Comp $_{i j}=1$ if the subject chooses the tournament in the third round and 0 if the subject chooses piece-rate. $C o h_{i j}$ is birth cohort dummy variables indicating cohort born in 1966 and 1977; Male $_{i j}$ is the male indicator. Coh ${ }_{i j} *$ Male $_{i j}$ are two interaction terms between the dummy variable for birth cohort 1966 and that for 1977 and the male dummy variables. Variables measuring ability and game characteristics/performance are included in the vector $W_{i j}$. These variables are risk aversion, over-confidence, IQ, performance, individuals sustainability to perform under pressure, the gender composition of the session, and the number of participants in each session. ${ }^{10}$ Individual characteristics are incorporated into the vector $X_{i j}$, including years of schooling, the individual's mother's years of schooling, and the number of siblings they have. $\varepsilon_{i j}$ denotes the random error term.

Thus, the coefficient $\kappa$ measures the gender difference in competitive inclination for the 1958 cohort, while $\kappa+\rho_{1966}$ and $\kappa+\rho_{1977}$ measure the gender differences in competitive inclination for the 1966 and 1977 cohorts, respectively.

We initially estimate Equation 1 for Beijing and Taipei separately with three different model specifications: (1) the simple model without controlling for $W_{i j}$ and $X_{i j}$; (2) the simple model plus $W_{i j}$, and (3) adding the additional control variables of $X_{i j}$. Table 3 reports the full regression results together with the gender gap in competitive choice for

\footnotetext{
${ }^{10}$ The 'risk aversion' variable is obtained from the risk game; 'over-confidence' is measured by the difference in self-assessed potential performance in the competition game and their actual performance; 'performance' and 'IQ' are measured by the number of correct answers in the second round and the simple Raven's test score; 'sustainability to pressure' is measured by a set of dummy variable indicating difference in performance under piece rate and tournament payment methods.
} 
each cohort. The results at the bottom panel of the table labeled 'gender difference by cohort' indicate that there is a negative gender gap for Beijing 1958 cohort. On average, without controlling for anything (column 1), the Beijing 1958 males are 14\% less likely to choose to compete than their female counterparts. For the same cohort in the Taipei sample (column 4), however, males are around 8.3\% more likely to compete than their female counterparts, though the coefficient is not precisely estimated.

Columns 2 and 5 report the estimates from Model 2, in which we control for other factors potentially contributing to the willingness to compete. These include individuals' competence in performing correct additions, risk aversion, overconfidence, potential ability to sustain pressure, and gender composition and the size of the game session. From columns 2 and 5, we see that the 1958 female cohort in Beijing is 14.9\% more competitively inclined, an increase from $14.1 \%$, while for the Taipei cohort the male advantage is more than halved. For the Beijing sample, the only other factors affecting whether individuals choose to compete are their adding-up ability (number of correct answers in round 2) and their ability to sustain pressure (difference in number of correct answers in Rounds 1 and 2). However, for the Taipei sample, we see that risk aversion, the Raven's test score, as well as whether the session attended is a single sex session, also play an important role. In columns 3 and 6 we control for further individual characteristics. Again, the female advantage for the Beijing 1958 cohort increased further to $15.9 \%$ while, for the same cohort in Taipei, the male advantage reduced to $3.7 \%$.

We now compare the competitive inclination of the 1958 Beijing women with their younger counterparts. The results from Model 1 (column 1) suggest that the 1966 women are equally competitive as the 1958 cohort, while the 1977 cohort is more competitive than their 1958 counterparts. However, once we control in Model 2 (column 2) for the competence level and other potential reasons for choosing to compete, the coefficients for both the 1966 and 1977 cohorts become negative but statistically insignificant. This suggests that women across cohorts are equally competitive. Further controlling for personal characteristics (column 3) the size of the negative coefficients increase, but none is precisely estimated. Nevertheless, the coefficient for the 1966 relative to 1958 cohort is reasonably large (-0.12). The situation is similar for the Taipei women.

We next estimate the following pooled regression for Beijing and Taipei shown in Equation (2). THis allows us to compare not only the gender gap in competitive incli- 
nation across cohorts within each region but also that between Beijing women and their Taipei counterparts.

$$
\begin{aligned}
\text { Comp }_{i j}= & \alpha+\beta_{j} \text { Coh }_{i j}+\kappa \text { Male }_{i j}+\rho_{j} \text { Coh }_{i j} * \text { Male }_{i j}+\theta W_{i j}+\gamma X_{i j}+\pi B_{i j} \\
& +\beta_{j}^{b} C_{i j} h_{i j} * B_{i j}+\kappa^{b} \text { Male }_{i j} * B_{i j}+\rho_{j}^{b} \text { Coh }_{i j} * \text { Male }_{i j} * B_{i j}+\theta^{b} W_{i j} * B_{i j} \\
& +\gamma^{b} X_{i j} * B_{i j}+\varepsilon_{i j}
\end{aligned}
$$

where $B$ is an indicator for Beijing sample and the superscript $b$ denotes the coefficient for Beijing sample.

Table A.1 in the appendix indicates how to interpret the coefficients from equation 2. The selected results from estimation of equation 2 are reported in Table A.2 and the implied differences in competitive inclination, both across cohorts within a region and across regions, are reported in Table 4.

The results here confirm those obtained from Table 3, namely that women in the 1958 Beijing cohort are more competitively inclined than their male counterparts, whereas controlling for all variables (Model 3 in Table 4) none of the other cohorts in either Beijing or Taipei exhibits significant gender difference.

Do these results indicate that the observed gender gap for the Beijing 1958 cohort is mainly due to the male 1958 group being less competitive than the women? We examine this issue in several steps. First, we examine whether women in Beijing 1958 cohort are more or less competitively inclined than their younger counterparts. The second panel of Table 4 reports these results. It shows that the 1958 women in Beijing are no less, if not more competitively inclined than the 1966 and 1977 cohort women in Beijing. In particular, relative to the 1966 women in Beijing, they are almost $12 \%$ more likely to choose to compete, although this is not precisely estimated.

Second, we compare women in Beijing with their respective cohort women in Taipei. These results are exhibited in the third panel. We show that women in the Beijing 1958, 1966 and 1967 cohorts are all more competitively inclined than their respective counterparts in Taipei. The differences in their competitive inclination are large. For the 1977 cohort, however, the difference is precisely estimated only in Model 2.

Third, using results from model 3 we also test whether women in the Beijing 1958 cohort are more competitively inclined than the Taipei 1958 males and both genders in the Taipei 1966 and 1977 cohorts. The test results confirm that they are indeed more 
competitively inclined than these other groups.

We now investigate if the pattern observed in our laboratory setting is consistent with real world outcomes. An important gender-equality measure should be labour force participation, However, the official retirement age for mainland China is 50-55 for women and 60 for men, while in Taiwan is it 60 for women and 65 for men. The 1958 cohort was aged 57 at the time the experiments were conducted, and at that time our mainland female cohort had reached retirement age while the mainland male cohort and both genders in Taiwan have not. Thus, it is hard to compare labour force participation rates across cohorts and regions. Therefore we instead use individuals' take-home income from workplaces (including wages, bonuses, subsidies or retirement income) and income from both workplaces and government (mainly for retirement income). Table 5 reports these average monthly incomes by cohort and gender as well as male/female income ratios. The data revealed in the table (bottom row of top panel) suggest that, on average, Beijing women bring home $37 \%$ less income than their male counterparts if we only count income they obtained from workplaces and work related pensions (the top panel, third column). If we also take into account pensions and other transfers from government, the ratio reduces to $25 \%$. In Taipei, however, the take home income gap between males and females is around $61 \%$ in both cases.

When we compare the gender income gap by cohort we find that, except for the 1958 Beijing cohort, the gender wage gaps $\left(\left(\right.\right.$ Wage $_{m} /$ Wage $\left.\left.f\right)-1\right)$ for all the cohorts in both Beijing and Taipei are positive. For the Beijing 1958 cohort, women bring home on average more income than their male counterparts. If we only count incomes from workplaces, the difference is a mere 1 percent. If we consider pensions from the government as well, the difference increases to 10 percent.

In the survey we also ask individuals whether they think their own income is more, less, or about the same as an individual at the same age, same education level but opposite gender. We report the proportion of each cohort/gender group's opinion for both Taipei and Beijing in the third panel of Table 5. In general, we see that more than $50 \%$ of individuals in both gender and all cohorts in Beijing reported that their income is the same as their opposite-gender counterparts. The ratio is slightly higher for older than younger cohorts. The proportion in each Taipei cohort choosing equal payment is substantially lower. Surprisingly a large proportion of women in the Taipei cohorts believes they earn 
more than their male counterparts.

\section{Mechanisms}

Alesina and Fuchs-Schundeln (2007) discussed the endogenous role political regimes play in forming people's tastes for public social policies. They provide strong evidence that there is a feedback effect from the regime on people's preferences. In our experiment, the finding that women in the 1958 Beijing cohort are more competitively inclined may well be related to this feedback effect. In this section we further explore the mechanisms through which women growing up under different regimes form different preferences.

To examine if there is a long lasting communist indoctrination effect, we follow Alesina and Fuchs-Schundeln (2007) and check if preferences towards government intervention in social and economic affairs differs across cohorts and regions. In our exit-survey, we asked subjects if they believe that government should play a role in reducing income inequality in general and if they support the view that the less intervention from the government to the economy the better. The answers are given on a scale of 1 to 5 , with 1 being strongly disagree and 5 being strongly agree. Using these data as the dependent variables we estimate using OLS a modified version of equation 2 without the game controls and added in log individual income into the vector $X_{i j}$. The selected results are reported in the first two columns of Table 6, where we report three panels: the top panel reports the selected estimated coefficients from the regressions of modified equation 2 , the middle panel reports the implied differences across cohorts and regions based on the top panel coefficients, and the bottom panel reports differences between Beijing women/men and Taipei women/men based on results from the regressions that look only at aggregated differences and disregard cohort variations.

The results for the state-intervention preference variables suggest that, in general, the Mainland Chinese female cohorts, relative to the Taiwanese female cohorts, are much more likely to support the view that the government should try to reduce income inequality and much less likely to think that the less government intervention in the economy the better. On a scale of 1 to 5 points, the three female cohorts are 1.4 to 1.9 points more likely to support government reducing inequality and 1.6 to 1.8 points less likely to think that less government intervention in the economy the better. These are very large differences, 
between $28 \%$ to $38 \%$ of the total scores. These results are largely consistent across the three female cohorts. If we examine the bottom panel, which treats male and female subjects in Beijing and Taipei as a single group, we see that this conclusion applies to males as well. Thus, after 40 years of market oriented economic reform, the society is still largely geared towards equality and government intervention. This finding is in line with that of (Alesina and Fuchs-Schundeln, 2007) - that communist propaganda has a long lasting effect. In addition, our results indicate that individuals who grew up subject to the heavy dose of indoctrination, and individuals who largely grew up with new ideology, all seem to be prefer more state intervention in social and economic affairs. This latter finding differs slightly from that of (Alesina and Fuchs-Schundeln, 2007) which revealed that in East Germany those born after 1975 have a much lower preference for government intervention relative to their older counterparts. This difference between their results and ours may relate to two broad sets of factors. First, after German reunification Communism was discredited and there was a large migration from East to West Germany. Second, in mainland China the Communist Party is still the ruling party, even though the economy largely operates under market economic rules.

Is the difference in gender competitive inclination and in the preference for government intervention for social and economic issues really a reflection of indoctrination? There is a small literature that discusses intergenerational transmission of cultural norms (see for example, Alberto and Verdier, 2000; Tabellini, 2010; and Nunn and Leonard, 2011). In the post-experiment survey, we follow this approach and ask respondents to pick from a list of qualities or attributes those that their parents and school encouraged when they were young. We report here the results from our examination of three attributes that are related to the competitive inclination and preference for inequality in general: 1. men and women are equal; 2 . be competitive; and 3 . be unselfish. We generate two dummy variables for each of these qualities: whether mother or school encouraged individuals to have these qualities (yes $=1,0$ otherwise). The modified version of equation 2 is estimated using a linear probability model (LPM) for ease of interpretation of the coefficients. The results for mothers' encouragement and schools' encouragement are reported in columns [3] to [8] of Table 6. The three panels separately report the regression coefficients; the implied differences across gender, cohorts and region; and the aggregated differences between Beijing and Taipei for females and males. 
The results on gender equality (both from mothers' and schools' teaching) show that there is no consistent gender difference within each Beijing cohorts. Relative to the 1958 Beijing females, those who were born later are consistently less likely to have either mother or school encourage them to believe in gender equality. Although the size of the differences are large (9\% to 13\%), none of the differences are precisely estimated. Relative to Taipei women, however, Beijing women in all three cohorts are more likely to have their parents or school to encourage them to have the view of gender equality. The difference in probability ranges from $70 \%$ to $74 \%$ for mothers' encouragement and $59 \%$ to $82 \%$ for schools' encouragement. This is not only the case for females, the bottom panel shows that Beijing males were equally more likely to have their mothers and schools to encourage them to adopt the view of gender equality than their Taipei counterparts.

Regarding being competitive, mainland parents do not seem to have prepared their children any more than their Taiwan counterparts. However, schools in Beijing did, but this seems to be more so for the later cohorts than for the 1958 cohort. Mainland parents and schools are more likely to teach their children to be unselfish than their Taiwan counterparts. This is true for all female and male cohorts. It is also true that the probability is higher for the 1958 Beijing cohort than that for the later Beijing cohort, but the differences are not statistically significant.

How did propaganda affect individuals' behaviour and preferences 40 years after the change of the regime? Psychologists have long been discussing how social norms about sex roles may affect children's personality characteristics and behavioural competencies to prepare them to fulfil the societal expectations so that they can perform those roles (see, for example, Horner, 1972; Fitzgerald and Betz, 1983).

Our post-experiment survey implemented the "Big Five inventory" (BFI), which consists of 44 questions designed to elicit individual's personality traits. The psychological literature has identified the overlap between extroversion and competitiveness (Hogan, 1986; Digman, 1990; Chen and Chang, 2011). Recent empirical studies on online game players also identified that individuals who have higher scores on openness, extroversion, and conscientiousness are more likely to be players (Teng, 2008). We examine across gender-cohort-region differences in the 'Big Five' personality by estimating equation 2 without control for $W_{i j}$ and $X_{i j}{ }^{11}$ The implied difference in personality traits derived

\footnotetext{
${ }^{11}$ The reason we include no personal control is because most of the controls are endogenous.
} 
from the estimated results are reported in Table 7.

We find that females in all Beijing cohorts are more extroverted than their male counterparts, though only the 1977 cohort exhibit statistically significant difference. More importantly, all three cohorts Beijing women are statistically significantly more extroverted than their Taipei counterparts. The aggregated estimation (the bottom panel of the table) also confirms that Beijing females are more extroverted than Taipei males and females and they are more extroverted than Beijing males. However, it does not seem to be the case that there are significant across cohort difference in extroversion. If anything, the 1958 cohort seems to be slightly less extroverted than their younger counterparts but the differences are not statistically significant.

With regard to Openness, for the 1958 and 1977 birth cohorts we observed statistically significant gender differences within the Beijing sample. Women are more open than men. Beijing women are also more open than Taipei women in every cohort, and the size of the difference is the largest for the 1958 cohort. Further, at the aggregated level, Beijing women have higher openness scores than their Beijing male, Taipei male, and Taipei female counterparts. Once again, we fail to detect across-cohort variations among Beijing females which may help to shed light on why the 1958 Beijing women are more competitive.

For agreeableness, Neuroticism, and Conscientiousness we find similar but less statistically significant pattens. The Beijing women seem to be more agreeable, less neurotic, and more conscientious than Beijing males, Taipei females and Taipei males.

These results provide some weak evidences that perhaps indoctrination at young age could affect individuals personality and through which affect individuals' behavour. To this end, more research is needed.

\section{Conclusions}

In the laboratory experiment reported in this paper we explored how evolving cultural norms in mainland China changed individuals' preferences. From 1949 onwards, China experienced dramatic changes in its socio-economic institutions that started with communist central planning and the deliberate establishment of new social norms, including the promotion of gender equality in place of the Confucian view of female 'inferiority'. 
Market-oriented reforms, begun in 1978, helped China achieve unprecedented economic growth and at the same time Marxist ideology was gradually replaced by the acceptance of individualistic free-market ideology. During this reform period, although the Communist Party remained firmly in place, many old traditions crept back, and social norms gradually changed again.

The subjects of our experiment were different birth cohorts of men and women who were exposed to one of the two regimes outlined above during their crucial developmentalage, and we investigated gender differences in their competitive choices. To summarise, our conjecture was that the cohort exposed to the most extreme gender-equality propaganda would not only behave differently from other cohorts in mainland China, but also from their counterparts in a society with similar ethnic and Confucian roots but with a divergent history from 1949 - Taiwan.

In particular we investigated gender differences in competitive choices for three different birth cohorts in Beijing, using their counterparts in Taipei (who were subject to the same original Confucian traditions) to control for the general time trend.

Our main results confirm: (i) that females in Beijing are significantly more likely to choose to compete than females from Taipei; (ii) that Beijing females from the 1958 birth cohort are more competitive than their male counterparts as well as more competitive than later Beijing birth cohorts; and (iii) that for Taipei there are no statistically significant differences across cohort or gender in willingness to compete.

In summary, our findings confirm that exposure to different institutions and social norms during the crucial developmental age changes individuals' behaviour. Our findings also provide further evidence that gender differences in economic preferences are not innately determined. 


\section{References}

Alberto, B. and T. Verdier (2000). 'beyond the melting pot: Cultural transmission, marriage, and the evolution of ethnic and religious traits. in Quarterly Journal of Economics 155(3), 955-88.

Alesina, A. and N. Fuchs-Schundeln (2007). Good-bye lenin (or not?): The effect of communism on peoples preferences. The American Economic Review 97(4), 1507-1536.

Alesina, A., P. Giuliano, and N. Nunn (2013). On the origins of gender roles: Women and the plough. The Quarterly Journal of Economics 128(2), 469-530.

Booth, A. L. and P. J. Nolen (2012). Choosing to compete: How different are girls and boys. Journal of Economic Behavior and Organization 81, 542-555.

Buser, T. (2012). The impact of the menstrual cycle and hormonal contraceptives on competitiveness. Journal of Economic Behavior and Organization 83, 1-10.

Cai, Huajian, K. V. and C. Sedikides (2012). A sociocultural approach to narcissism: the case of modern china. European Journal of Personality 26, 529-535.

Chen, Xiao-Ping, X. X. and S. Chang (2011). Cooperative and competitive orientation among chines people: Scale development and validation. Management and Organization Review 7(2), 353-379.

Croll, E. (1983). Chinese Women since Mao. London and New York: Zed Books.

Croll, E. (1995). Changing Identities of Chinese Women: Rhetoric, Experience, and SelfPerception in Twentieth-Century China. Hong Kong University Press, London and New Jersey: Zed Books.

Deng, Z. and D. J. Treiman (1997). The impact of the Cultural Revolution on trends in educational attainment in the People's Republic of China. American Journal of Sociology 103(2), 391-428.

Digman, M. J. (1990). Personality structure: Emergence of the five-factor model. Annual Review of Psychology 41(1), 417440.

Fernandez, R., A. Fogli, and C. Olivetti (2004). Mothers and sons: Preference formation and female labor force dynamics. Quarterly Journal of Economics 119(4), 1249-1299.

Fitzgerald, L. and N. Betz (1983). Issues in the vocational psychology of women. In J. B. Walsh and S. H. Osipow (Eds.), Handbook of Vocational Psychology, pp. 83-151. Hillsdale, NJ: Erlbaum.

Gneezy, U., K. L. Leonard, and J. A. List (2009). Gender differences in competition: evidence from a matrilineal and a patriarchal society. Econometrica $77(5), 1637-1664$.

Gneezy, U., M. Niederle, and A. Rustichini (2003). Performance in competitive environments: Gender differences. The Quarterly Journal of Economics 118(3), 1049-1074.

Gneezy, U. and J. Potters (1997). An experiment on risk taking and evaluation periods. Quarterly Journal of Economics 112(2), 631-645.

Gneezy, U. and A. Rustichini (2004). Gender and competition at a young age. American Economic Review Papers and Proceedings 94(2), 377-381. 
Guiso, L., P. Sapienza, and L. Zingales (2006). Does culture affect economic outcomes? The Journal of Economic Perspectives 20(2), 23-48.

Hinton, W. (1966). Fanshen: A Documentary of Revolution in a Chinese Village. New York: Vintage Books.

Hofstede, G. and G. J. Hofstede (2005). Cultures and Organizations: Software of the Mind (Rev. 2nd ed.). New York: McGraw-Hill.

Hogan, R. (1986). Hogan Personality Inventory. Minneapolis, MN: National Computer Systems.

Horner, M. (1972). Toward an understanding of achievement-related conflicts in women. Journal of Social Issues 28(2), 157175.

Little, D. (2011). Marxism, communism, and women. Available at http://wwwpersonal.umd.umich.edu/delittle/.

Liu, E. M., J. Meng, and J. T. Wang (2014). Confucianism and preferences: Evidence from lab experiments in taiwan and china. Journal of Economic Behavior and Organization 104(2), $106-122$.

Lu, X. (2004). Rhetoric of the Chinese Cultural Revolution: The Impact on Chinese Thought, Culture, and Communication. Univercity of South Carolina Press.

Ma, L. (1995). The Culture of Yi Women. Sichuan Minzu Chubanshe.

Manski, C. F. (2000). Economic analysis of social interactions. The Journal of Economic Perspectives 14(3), 115-136.

Meng, X. (2000). Institutions and culture: Womens economic position in mainland china and taiwan. Manuscript, Department of Economics, Research School of Pacific and Asian Studies, Australian National University.

Meng, X. and R. G. Gregory (2002). The impact of interrupted education on subsequent educational attainment: A cost of the Chinese Cultural Revolution. Economic Development and Cultural Change 50(4), 935-59.

Meng, X. and M. Kidd (1997). Labour market reform and the changing structure of wage determination in china's state sector during the 1980s. Journal of Comparative Economics 25(3), 403-421.

Mow, S., T. Jie, and Z. Bijun (2004). Holding up Half the Sky: Chinese Women Past, Present, and Future. Feminist Press at the City University of New York.

Niederle, M. and L. Vesterlund (2007). Do women shy away from competition? do men compete too much? Quarterly Journal of Economics 122(1), 10671101.

Niida, N. (1964). Land reform and new marriage law in china. The Developing Economies 2(1), $13-15$.

Nunn, N. and W. Leonard (2011). The slave trade and the origins of mistrust in africa. American Economic Review 101(7), 3221-3253.

Raven, J. (2000). The raven's progressive matrices: change and stability over culture and time. Cognitive Psychology 41, 1-48. 
Sutter, M. and D. Gltzle-Rutzler (2015). Gender differences in the willingness to compete emerge early in life and persist. Management Science 61(10), 2339-2354.

Tabellini, G. (2010). Culture and institutions: Economic development in the regions of europe. Journal of the European Economic Association (4), 677-716.

Teng, C.-I. (2008). Personality differences between online game players and nonplayers in a student sample. Cyber Psychology and Behavior (2), 232-234.

Tseng, P.-s. (1992). The chinese women: past and present. In Y. N. Li (Ed.), Chinese Women Through Chinese Eyes. An East Gate Book, M. E. Sharpe, Inc.

Xu, Y. and T. Hamamura (2014). Folk beliefs of cultural changes in china. Frontiers in Psychology 5, 1066.

Yao, Y. and W. You (2016). Half skyy over china: Women's political participation and sex imbalances: 1950-1990. Unpublished Manuscript, Peking University.

Zhang, J., J. Han, P.-W. Liu, and Y. Zhao (2008). Trend in the gender earnings differential in urban China, 1988-2004. Industrial and Labor Relations Review.

Zhang, Y. J. (2015). Culture, institutions, and the gender gap in competitive inclination: evidence from the communist experiment in china. Available at SSRN: http://ssrn.com/abstract=2268874 or http://dx.doi.org/10.2139/ssrn.2268874. 
Table 1: Summary Statistics

\begin{tabular}{|c|c|c|c|c|}
\hline & \multicolumn{2}{|c|}{ Beijing } & \multicolumn{2}{|c|}{ Taipei } \\
\hline & Females & Males & Females & Males \\
\hline & \multicolumn{4}{|c|}{ Number of observations } \\
\hline 1958 & 57 & 41 & 66 & 65 \\
\hline 1966 & 57 & 60 & 62 & 56 \\
\hline \multirow[t]{2}{*}{1977} & 61 & 58 & 56 & 54 \\
\hline & \multicolumn{4}{|c|}{ Years of schooling } \\
\hline 1958 & 11.94 & 12.42 & 10.91 & 12.20 \\
\hline 1966 & 12.68 & 12.59 & 12.74 & 12.89 \\
\hline \multirow[t]{2}{*}{1977} & 14.41 & 14.09 & 14.80 & 14.04 \\
\hline & \multicolumn{4}{|c|}{$\underline{\text { Raven Scores }}$} \\
\hline 1958 & 4.27 & 5.16 & 6.29 & 6.25 \\
\hline 1966 & 5.47 & 5.90 & 6.94 & 7.30 \\
\hline \multirow[t]{2}{*}{1977} & 6.75 & 7.55 & 7.69 & 8.02 \\
\hline & \multicolumn{4}{|c|}{ Mother's years of schooling } \\
\hline 1958 & 6.64 & 6.23 & 4.55 & 4.15 \\
\hline 1966 & 7.544 & 8.02 & 4.9 & 5.82 \\
\hline \multirow[t]{2}{*}{1977} & 10.38 & 10.41 & 8.53 & 8.69 \\
\hline & \multicolumn{4}{|c|}{ Number of siblings } \\
\hline 1958 & 2.98 & 2.49 & 4.31 & 3.41 \\
\hline 1966 & 1.84 & 1.73 & 3.14 & 2.91 \\
\hline \multirow[t]{2}{*}{1977} & 0.63 & 0.71 & 2.53 & 1.70 \\
\hline & \multicolumn{4}{|c|}{ Marital status } \\
\hline Married & 88.00 & 91.82 & 62.50 & 68.57 \\
\hline De-facto & 2.29 & 0.63 & 0.54 & 1.14 \\
\hline Single & 2.86 & 2.52 & 24.46 & 25.14 \\
\hline Divorced & 5.71 & 5.03 & 7.61 & 5.14 \\
\hline Widowed & 1.14 & 0.00 & 4.89 & 0.00 \\
\hline
\end{tabular}

Notes: Authors' own calculation from the data 
Table 2: Summary Statistics for the Competition Game

\begin{tabular}{|c|c|c|c|c|c|c|}
\hline \multirow[b]{3}{*}{ Beijing } & \multicolumn{6}{|c|}{ Probability of choosing to compete in Round 3} \\
\hline & \multicolumn{2}{|c|}{ Females } & \multicolumn{2}{|c|}{ Males } & \multicolumn{2}{|c|}{ Females-Males } \\
\hline & Obs. & Mean & Obs & Mean & Diff & T-ratio \\
\hline$\overline{1958}$ & 57 & 0.26 & 41 & 0.12 & 0.14 & 1.72 \\
\hline 1966 & 57 & 0.26 & 60 & 0.45 & -0.19 & 2.13 \\
\hline 1977 & 61 & 0.44 & 58 & 0.47 & -0.02 & 0.25 \\
\hline \multicolumn{7}{|l|}{ Taipei } \\
\hline$\overline{1958}$ & 66 & 0.42 & 65 & 0.51 & -0.08 & 0.95 \\
\hline 1966 & 62 & 0.45 & 56 & 0.54 & -0.08 & 0.91 \\
\hline \multirow[t]{4}{*}{1977} & 56 & 0.59 & 54 & 0.57 & 0.02 & 0.16 \\
\hline & & Beijing & & & Taipei & \\
\hline & Males & Females & Diff & Males & Females & Diff \\
\hline & \multicolumn{6}{|c|}{ Number of correct answers in Round 1} \\
\hline 1958 & 5.20 & 7.30 & $2.103^{* * *}$ & 11.73 & 11.44 & -0.299 \\
\hline 1966 & 9.45 & 9.53 & 0.076 & 11.45 & 12.37 & 0.925 \\
\hline \multirow[t]{2}{*}{1977} & 9.94 & 11.46 & $1.511^{* *}$ & 11.35 & 12.02 & 0.666 \\
\hline & \multicolumn{6}{|c|}{ Number of correct answers in Round 2} \\
\hline 1958 & 6.98 & 8.19 & $1.217^{* *}$ & 13.06 & 13.08 & -0.014 \\
\hline 1966 & 10.37 & 11.11 & 0.738 & 13.25 & 13.45 & 0.202 \\
\hline 1977 & 11.69 & 12.80 & 1.114 & 12.69 & 13.07 & 0.386 \\
\hline
\end{tabular}

Notes: Authors' own calculation from the data 
Table 3: Estimated Results for Equation (1)

\begin{tabular}{|c|c|c|c|c|c|c|}
\hline & \multicolumn{3}{|c|}{ Beijing } & \multicolumn{3}{|c|}{ Taipei } \\
\hline & [1] & {$[2]$} & {$[3]$} & {$[4]$} & {$[5]$} & {$[6]$} \\
\hline \multirow[t]{2}{*}{ Dummy for males } & $-0.141^{*}$ & $-0.149^{*}$ & $-0.159^{*}$ & 0.083 & 0.040 & 0.037 \\
\hline & {$[0.078]$} & {$[0.087]$} & {$[0.087]$} & {$[0.088]$} & {$[0.081]$} & {$[0.085]$} \\
\hline \multirow[t]{2}{*}{ Dummy for 1966} & 0.000 & -0.092 & -0.119 & 0.027 & -0.042 & -0.049 \\
\hline & {$[0.083]$} & {$[0.088]$} & {$[0.093]$} & {$[0.088]$} & {$[0.082]$} & {$[0.085]$} \\
\hline \multirow[t]{2}{*}{ Dummy for 1977} & $0.179^{* *}$ & -0.003 & -0.057 & $0.165^{*}$ & 0.046 & 0.010 \\
\hline & {$[0.087]$} & {$[0.088]$} & {$[0.103]$} & {$[0.090]$} & {$[0.088]$} & {$[0.093]$} \\
\hline \multirow[t]{2}{*}{ Male*1966 } & $0.328^{* * *}$ & $0.295^{* *}$ & $0.299^{* *}$ & 0.001 & 0.026 & 0.014 \\
\hline & [0.117] & {$[0.121]$} & {$[0.124]$} & {$[0.127]$} & {$[0.116]$} & {$[0.119]$} \\
\hline \multirow[t]{2}{*}{ Male*1977 } & 0.164 & $0.201^{*}$ & $0.212^{*}$ & -0.099 & -0.047 & -0.058 \\
\hline & {$[0.121]$} & {$[0.118]$} & {$[0.120]$} & {$[0.129]$} & {$[0.118]$} & {$[0.117]$} \\
\hline \multirow[t]{2}{*}{ Dummy for round $1=$ round 2} & & $0.191^{* *}$ & $0.200^{* *}$ & & 0.017 & 0.016 \\
\hline & & {$[0.078]$} & {$[0.080]$} & & {$[0.072]$} & {$[0.072]$} \\
\hline \multirow[t]{2}{*}{ Dummy for round $1<2$} & & 0.040 & 0.045 & & $0.138^{* *}$ & $0.146^{* *}$ \\
\hline & & {$[0.066]$} & {$[0.067]$} & & {$[0.064]$} & {$[0.065]$} \\
\hline \multirow[t]{2}{*}{ Dummy for round $2=$ round 3} & & 0.026 & 0.022 & & 0.000 & 0.000 \\
\hline & & {$[0.071]$} & {$[0.071]$} & & {$[0.070]$} & {$[0.070]$} \\
\hline \multirow[t]{2}{*}{ Dummy for round $2<3$} & & -0.054 & -0.055 & & -0.013 & -0.023 \\
\hline & & {$[0.060]$} & {$[0.060]$} & & {$[0.055]$} & {$[0.056]$} \\
\hline \multirow[t]{2}{*}{ Risk aversion (switching point) } & & -0.001 & -0.001 & & $-0.002^{* * *}$ & $-0.002^{* * *}$ \\
\hline & & {$[0.001]$} & {$[0.001]$} & & {$[0.001]$} & {$[0.001]$} \\
\hline \multirow[t]{2}{*}{ No. of correct answer in round 2} & & $0.035^{* * *}$ & $0.035^{* * *}$ & & $0.042^{* * *}$ & $0.043^{* * *}$ \\
\hline & & {$[0.009]$} & {$[0.009]$} & & {$[0.006]$} & {$[0.007]$} \\
\hline \multirow[t]{2}{*}{ Raven test score } & & 0.019 & 0.017 & & $0.042^{* * *}$ & $0.041^{* * *}$ \\
\hline & & {$[0.012]$} & {$[0.012]$} & & {$[0.012]$} & {$[0.012]$} \\
\hline \multirow[t]{2}{*}{ Over-confidence } & & 0.037 & 0.032 & & 0.030 & 0.033 \\
\hline & & {$[0.026]$} & {$[0.026]$} & & {$[0.024]$} & {$[0.024]$} \\
\hline \multirow[t]{2}{*}{ Dummy for single sex sessions } & & -0.046 & -0.047 & & $0.120^{* *}$ & $0.105^{* *}$ \\
\hline & & {$[0.057]$} & {$[0.058]$} & & {$[0.050]$} & {$[0.051]$} \\
\hline \multirow[t]{2}{*}{ No. of participants in the session } & & -0.005 & -0.005 & & 0.008 & 0.008 \\
\hline & & {$[0.004]$} & {$[0.004]$} & & {$[0.005]$} & {$[0.005]$} \\
\hline \multirow[t]{2}{*}{ Years of schooling } & & & 0.007 & & & -0.010 \\
\hline & & & {$[0.010]$} & & & {$[0.007]$} \\
\hline \multirow[t]{2}{*}{ Mother's years of schooling } & & & 0.000 & & & $0.011^{*}$ \\
\hline & & & {$[0.006]$} & & & {$[0.007]$} \\
\hline \multirow[t]{2}{*}{ No. of siblings } & & & -0.018 & & & -0.013 \\
\hline & & & {$[0.020]$} & & & {$[0.017]$} \\
\hline Observations & 334 & 332 & 330 & 359 & 356 & 354 \\
\hline \multirow[t]{2}{*}{ R-squared } & 0.065 & 0.150 & 0.151 & 0.015 & 0.223 & 0.231 \\
\hline & \multicolumn{6}{|c|}{ Test for gender difference (male-female) by cohort } \\
\hline Cohort 1958 & $-0.141^{*}$ & $-0.149^{*}$ & $-0.159^{*}$ & 0.083 & 0.040 & 0.037 \\
\hline SE & {$[0.078]$} & {$[0.087]$} & {$[0.087]$} & {$[0.088]$} & {$[0.081]$} & {$[0.085]$} \\
\hline Cohort 1966 & $0.187^{* *}$ & 0.146 & 0.140 & 0.084 & 0.066 & 0.051 \\
\hline $\mathrm{P}$ values $\left(\kappa+\rho_{66}=0\right)$ & {$[0.034]$} & {$[0.106]$} & {$[0.130]$} & {$[0.365]$} & {$[0.470]$} & {$[0.581]$} \\
\hline Cohort 1977 & 0.023 & 0.052 & 0.053 & -0.016 & -0.007 & -0.021 \\
\hline $\mathrm{P}$ values $\left(\kappa+\rho_{77}=0\right)$ & {$[0.804]$} & {$[0.565]$} & {$[0.554]$} & {$[0.873]$} & {$[0.936]$} & {$[0.815]$} \\
\hline
\end{tabular}

Notes: Authors' own estimations. 
Table 4: Gender gap in competitive inclination across cohorts and regions

\begin{tabular}{lcccccc}
\hline \hline \multirow{2}{*}{ Pooled sample estimation } & \multicolumn{2}{c}{ Model 1 } & \multicolumn{2}{c}{ Model 2} & \multicolumn{2}{c}{ Model 3 } \\
& Taipei & Beijing & Taipei & Beijing & Taipei & Beijing \\
\hline 1958 male vs. female & 0.083 & $-0.142^{*}$ & 0.039 & $-0.151^{*}$ & 0.037 & $-0.159^{*}$ \\
& {$[0.088]$} & $(0.075)$ & {$[0.081]$} & $(0.082)$ & {$[0.085]$} & $(0.069)$ \\
1966 male vs. female & 0.084 & $0.186^{* *}$ & 0.064 & $0.148^{*}$ & 0.051 & 0.139 \\
& $(0.364)$ & $(0.031)$ & $(0.477)$ & $(0.096)$ & $(0.577)$ & $(0.123)$ \\
1977 male vs. female & -0.016 & 0.022 & -0.008 & 0.051 & -0.019 & 0.053 \\
& $(0.873)$ & $(0.804)$ & $(0.929)$ & $(0.568)$ & $(0.815)$ & $(0.552)$ \\
\hline 1966 female vs 1958 female & 0.027 & 0.000 & -0.042 & -0.095 & -0.049 & -0.119 \\
& {$[0.088]$} & $(0.272)$ & {$[0.082]$} & $(0.272)$ & {$[0.085]$} & $(0.194)$ \\
1977 female vs. 1958 female & $0.165^{*}$ & 0.179 & 0.045 & -0.004 & 0.010 & -0.057 \\
& {$[0.090]$} & $(0.272)$ & {$[0.088]$} & $(0.965)$ & {$[0.093]$} & $(0.582)$ \\
\hline BJ 1958 female vs. TP 1958 female & $-0.161^{*}$ & $0.786^{* * *}$ & $0.643^{*}$ \\
& {$[0.085]$} & {$[0.286]$} & {$[0.338]$} \\
BJ 1966 female vs. TP 1966 female & $-0.188^{* *}$ & $0.733^{* *}$ & $0.573^{*}$ \\
& $(0.030)$ & $(0.013)$ & $(0.093)$ \\
BJ 1977 female vs. TP 1977 female & -0.002 & $0.737^{* *}$ & 0.576 \\
& $(0.112)$ & $(0.016)$ & $(0.106)$ \\
\hline \hline
\end{tabular}

Notes: Figures in the squared brackets are standard errors obtained directly from estimation of equation 2 . Those in the parentheses are p-values from the joint significant tests.

Table 5: Gender Income Gap

\begin{tabular}{|c|c|c|c|c|c|c|}
\hline & \multicolumn{3}{|c|}{ Beijing } & \multicolumn{3}{|c|}{ Taipei } \\
\hline & Males & Females & Male/Female & Males & Females & Male/Female \\
\hline & \multicolumn{6}{|c|}{ All income from work places (including retirment income) } \\
\hline 1958 & 3729 & 3755 & 0.99 & 7615 & 3888 & 1.95 \\
\hline 1966 & 6210 & 4170 & 1.48 & 11035 & 6378 & 1.73 \\
\hline 1977 & 7518 & 5242 & 1.43 & 9237 & 7128 & 1.29 \\
\hline \multirow[t]{2}{*}{ Total } & 6047 & 4408 & 1.37 & 9228 & 5746 & 1.60 \\
\hline & \multicolumn{6}{|c|}{ Income from workplaces and government } \\
\hline 1958 & 4529 & 5036 & 0.90 & 7496 & 4017 & 1.87 \\
\hline 1966 & 6324 & 4462 & 1.41 & 11035 & 6220 & 1.77 \\
\hline 1977 & 7518 & 5567 & 1.35 & 9308 & 7176 & 1.30 \\
\hline \multirow{4}{*}{ Total } & 6296 & 5034 & 1.25 & 9188 & 5721 & 1.61 \\
\hline & \multicolumn{6}{|c|}{ Relative to a person of opposite sex with same age/edu, your income is } \\
\hline & \multicolumn{3}{|c|}{ Beijing } & \multicolumn{3}{|c|}{ Taipei } \\
\hline & More & Less & Same & More & Less & Same \\
\hline \multicolumn{7}{|c|}{ Males } \\
\hline 1958 & 26.83 & 14.63 & 58.54 & 31.15 & 29.51 & 39.34 \\
\hline 1966 & 25.00 & 20.00 & 55.00 & 32.14 & 35.71 & 32.14 \\
\hline 1977 & 27.59 & 15.52 & 56.90 & 31.48 & 27.78 & 40.74 \\
\hline \multicolumn{7}{|c|}{ Females } \\
\hline 1958 & 33.33 & 8.77 & 57.89 & 38.71 & 22.58 & 38.71 \\
\hline 1966 & 33.33 & 10.53 & 56.14 & 59.02 & 11.48 & 29.51 \\
\hline 1977 & 37.70 & 9.84 & 52.46 & 50.91 & 14.55 & 34.55 \\
\hline
\end{tabular}


Table 6: Results from subjective questions

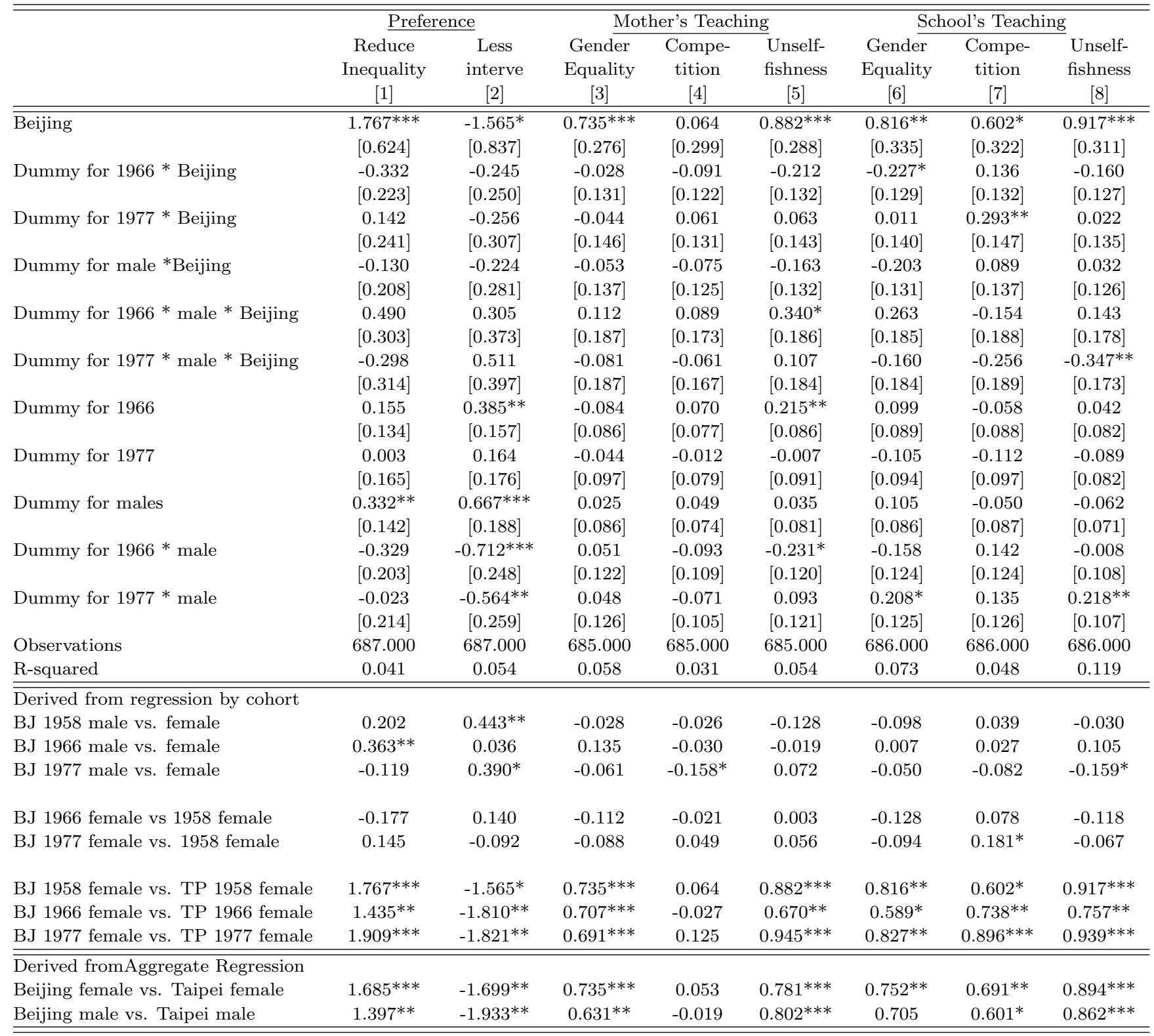

Notes: Notes: The middle panel is calculated based on the coefficients from the top panel of the table while the regression coefficients used to calculate the bottom panel results are not shown here. Most of the significant levels in the middle and bottom panels are based on the p-value from joint significant tests except for the rows labeled "Beijing 1958 female vs. Taipei 1958 female" and “'Beijing female vs. Taipei female', which are directly obtained from the coefficients for Beijing dummy variable in each regression and the significance level is based on t-statistics. 
Table 7: Derived differences in personality traits by gender, cohort and region

\begin{tabular}{|c|c|c|c|c|c|}
\hline Derived from regression by coh & Ext & Open & Agr & Neur & Cons \\
\hline 1958 male vs. female & -0.122 & $-0.130^{* *}$ & $-0.244^{* *}$ & -0.015 & -0.138 \\
\hline 1966 male vs. female & -0.016 & 0.074 & -0.005 & -0.110 & $0.160^{*}$ \\
\hline 1977 male vs. female & $-0.205^{* *}$ & $-0.073^{*}$ & $-0.262^{* *}$ & 0.027 & $-0.182^{*}$ \\
\hline 1966 female vs 1958 female & 0.014 & -0.025 & -0.138 & 0.028 & -0.113 \\
\hline 1977 female vs. 1958 female & 0.136 & $0.167^{*}$ & 0.109 & -0.054 & 0.137 \\
\hline BJ 1958 female vs. TP 1958 female & $0.238^{* * *}$ & $0.325^{* * *}$ & 0.026 & -0.093 & -0.001 \\
\hline BJ 1966 female vs. TP 1966 female & $0.348^{* * *}$ & $0.189^{* *}$ & -0.073 & $-0.216^{* * *}$ & -0.101 \\
\hline BJ 1977 female vs. TP 1977 female & $0.235^{* *}$ & $0.217^{* *}$ & $0.219^{* * *}$ & $-0.318^{* * *}$ & 0.121 \\
\hline \multicolumn{6}{|l|}{ Derived from aggregate regression } \\
\hline Beijing female vs. Taipei female & $0.279^{* * *}$ & $0.252^{* * *}$ & 0.058 & $-0.208^{* * *}$ & 0.010 \\
\hline Beijing male vs. Taipei male & 0.045 & -0.087 & -0.040 & -0.039 & $-0.045^{*}$ \\
\hline Beijing females vs Taipei males & $0.387^{* * *}$ & $0.382^{* * *}$ & $0.224^{* *}$ & $-0.174^{*}$ & 0.055 \\
\hline Beijing male vs Beijing female & $-0.108^{*}$ & $-0.130^{* *}$ & $-0.166^{* * *}$ & -0.034 & -0.045 \\
\hline
\end{tabular}

Notes: Derived from authors' own estimation of regressions reported in Appendix Table A.3. 
Figure 1: Density of the phrases "half the sky" and "gender equality" in "People's Daily"

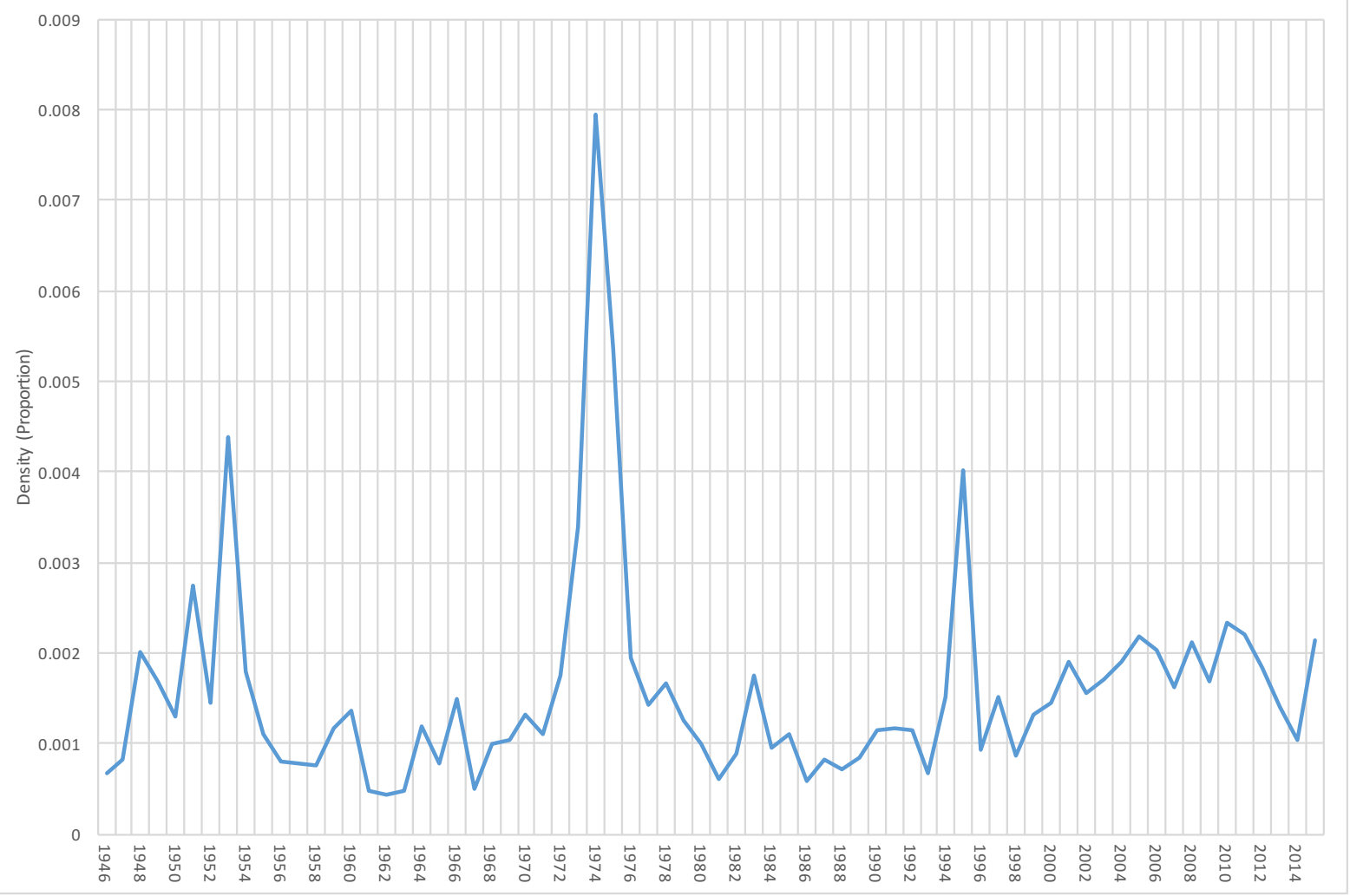

Figure 2: Labour force participation for Mainland China and Taiwan
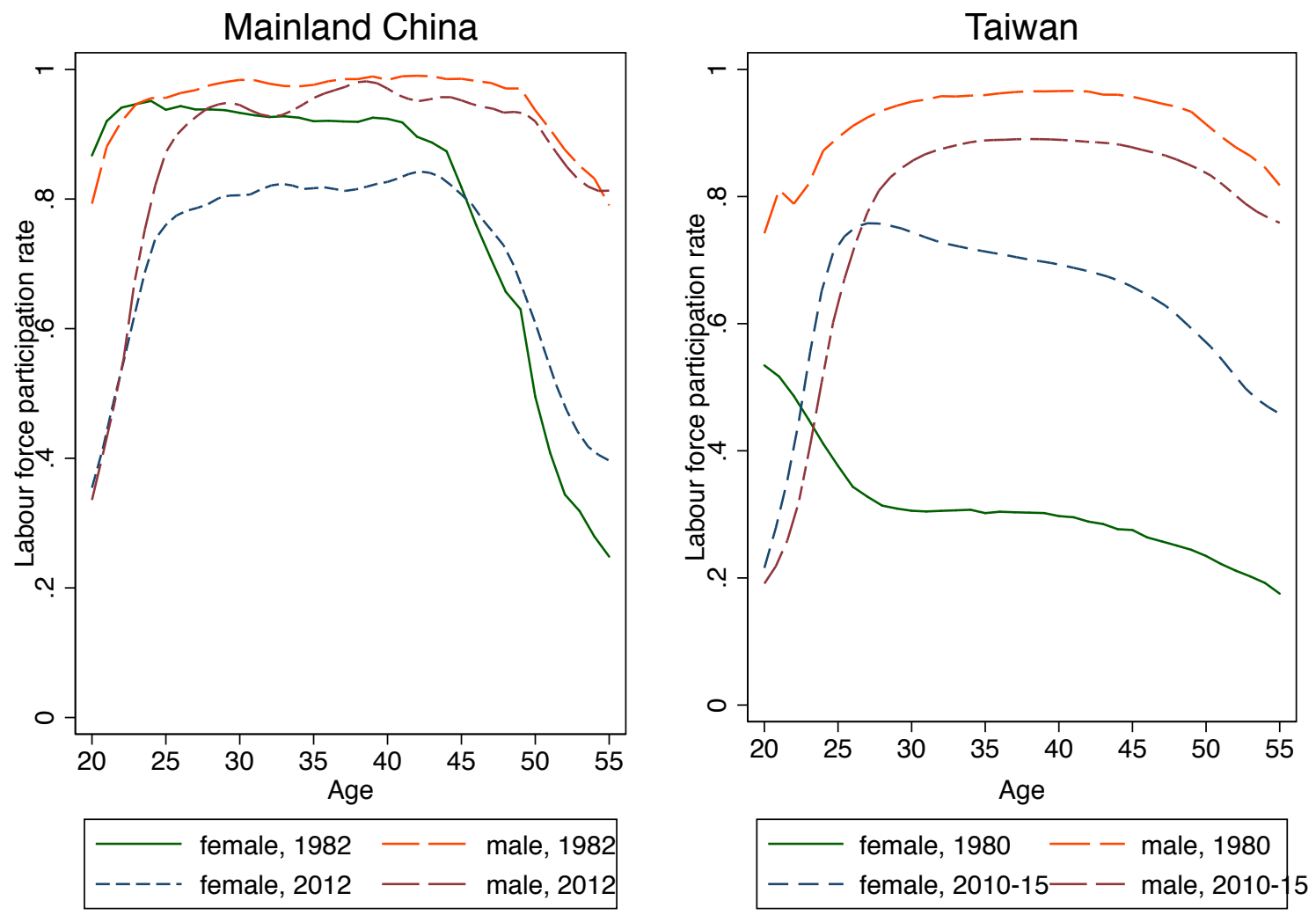
Figure 3: Cumulative Density Function: Number of correct answers Round 1
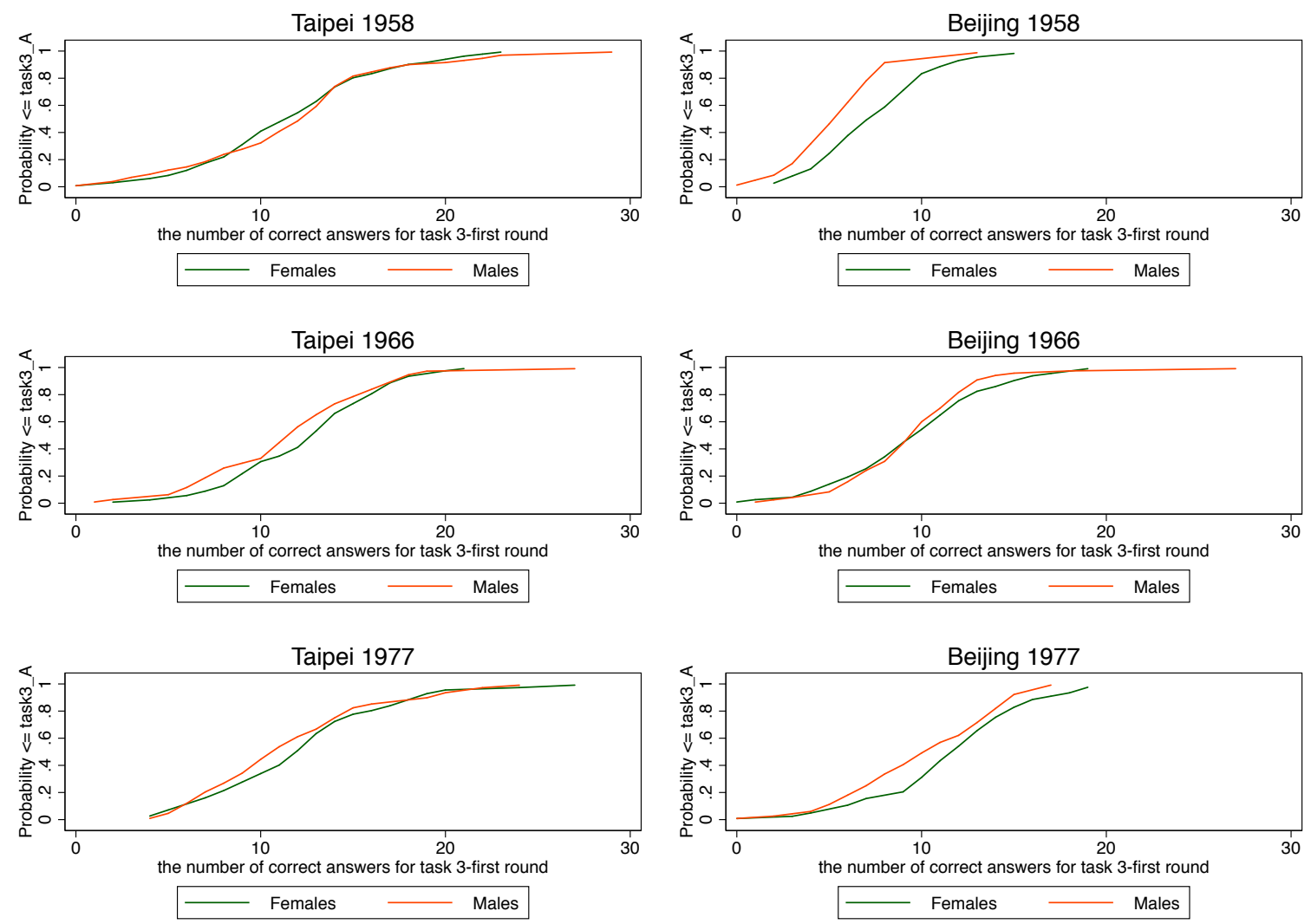
Figure 4: Cumulative Density Function: Number of correct answers Round 2
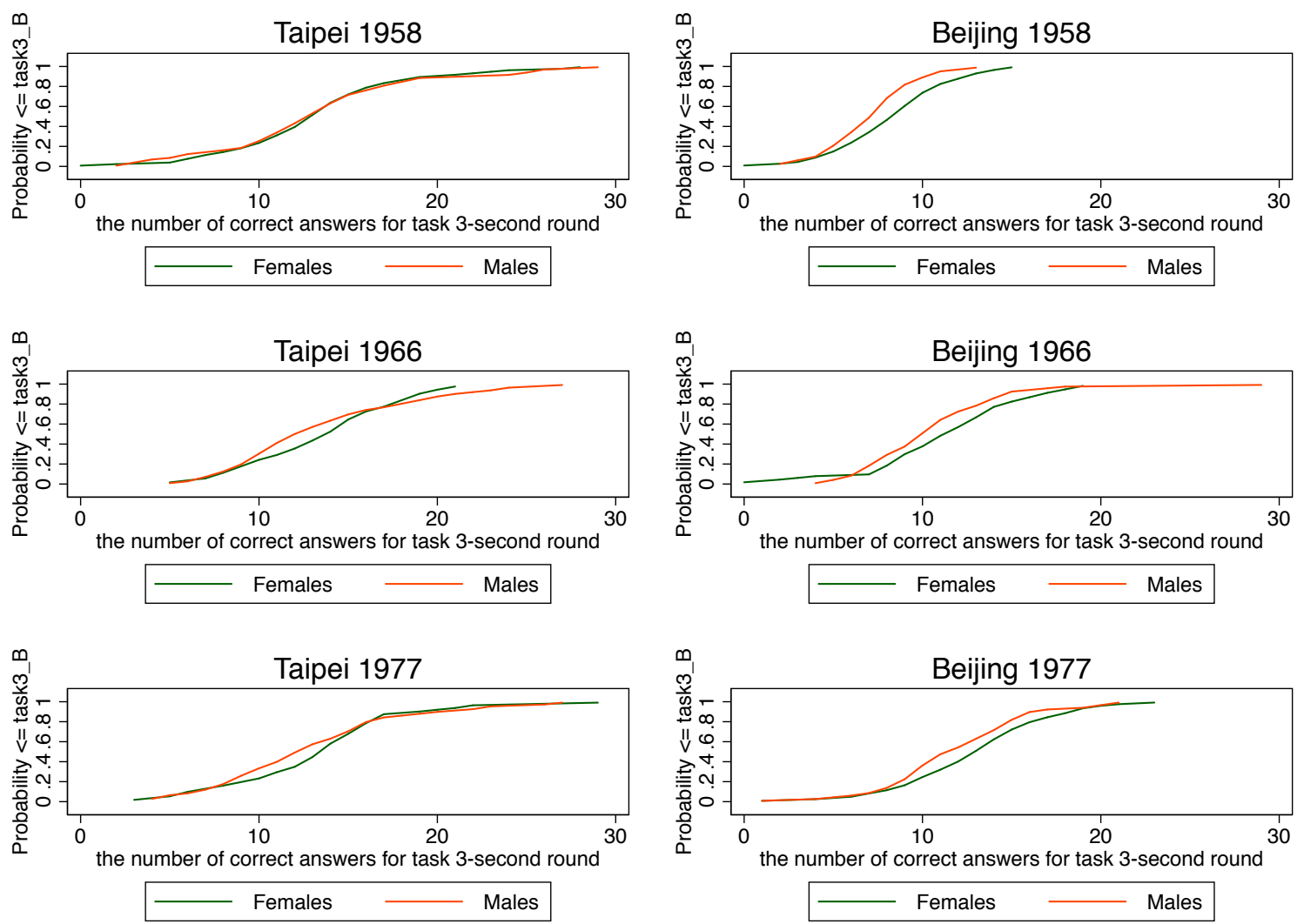


\section{A Appendix}

Table A.1: Interpretation of the coefficiets in Equation (2)

\begin{tabular}{|c|c|c|}
\hline Taipei & Females & Males \\
\hline 1958 & $\alpha$ & $\alpha+\kappa$ \\
\hline 1966 & $\alpha+\beta_{66}$ & $\alpha+\kappa+\beta_{66}+\rho_{66}$ \\
\hline 1977 & $\alpha+\beta_{77}$ & $\alpha+\kappa+\beta_{77}+\rho_{77}$ \\
\hline \multicolumn{3}{|l|}{ Beijing } \\
\hline 1958 & $\alpha+\pi$ & $\alpha+\pi+\kappa+\kappa^{b}$ \\
\hline 1966 & $\alpha+\pi+\beta_{66}+\beta_{66}^{b}$ & $\alpha+\pi+\kappa+\kappa^{b}+\beta_{66}+\beta_{66}^{b}+\rho_{66}+\rho_{66}^{b}$ \\
\hline \multirow[t]{2}{*}{1977} & $\alpha+\pi+\beta_{77}+\beta_{77}^{b}$ & $\alpha+\pi+\kappa+\kappa^{b}+\beta_{77}+\beta_{77}^{b}+\rho_{77}+\rho_{77}^{b}$ \\
\hline & Taipei & Beijing \\
\hline 1958 male vs. female & $\kappa$ & $\kappa+\kappa^{b}$ \\
\hline 1966 male vs. female & $\kappa+\rho_{66}$ & $\kappa+\kappa^{b}+\rho_{66}+\rho_{66}^{b}$ \\
\hline 1977 male vs. female & $\kappa+\rho_{77}$ & $\kappa+\kappa^{b}+\rho_{77}+\rho_{77}^{b}$ \\
\hline 1966 female vs 1958 female & $\beta_{66}$ & $\beta_{66}+\beta_{66}^{b}$ \\
\hline 1977 female vs. 1958 female & $\beta_{77}$ & $\beta_{77}+\beta_{77}^{b}$ \\
\hline & \multicolumn{2}{|c|}{ Beijing Females vs. Taipei Females } \\
\hline BJ 1958 female vs. TP 1958 female & \multicolumn{2}{|c|}{$\pi$} \\
\hline BJ 1966 female vs. TP 1966 female & \multicolumn{2}{|r|}{$\pi+\beta_{66}^{b}$} \\
\hline BJ 1958 female vs. TP 1958 female & \multicolumn{2}{|r|}{$\pi+\beta_{77}^{b}$} \\
\hline
\end{tabular}

Notes: Derived from Equation 2. 
Table A.2: Selected results from estimation of equation 2

\begin{tabular}{lccc}
\hline \hline & Model 1 & Model 2 & Model 3 \\
\hline Dummy for males & 0.083 & 0.039 & 0.037 \\
Dummy for male *Beijing & {$[0.088]$} & {$[0.081]$} & {$[0.085]$} \\
& $-0.225^{*}$ & -0.190 & -0.196 \\
Dummy for 1966 & {$[0.117]$} & {$[0.119]$} & {$[0.122]$} \\
& 0.027 & -0.042 & -0.049 \\
Dummy for 1977 & {$[0.088]$} & {$[0.082]$} & {$[0.085]$} \\
& $0.165^{*}$ & 0.045 & 0.010 \\
Dummy for $1966^{*}$ Beijing & {$[0.090]$} & {$[0.088]$} & {$[0.093]$} \\
& -0.027 & -0.053 & -0.070 \\
Dummy for $1977^{*}$ Beijing & {$[0.121]$} & {$[0.119]$} & {$[0.124]$} \\
& 0.014 & -0.049 & -0.067 \\
Dummy for $1966 *$ male & {$[0.125]$} & {$[0.124]$} & {$[0.139]$} \\
& 0.001 & 0.025 & 0.014 \\
Dummy for $1977^{*}$ male & {$[0.128]$} & {$[0.116]$} & {$[0.118]$} \\
Dummy for $1966 *$ male * Beijing & -0.099 & -0.047 & -0.058 \\
& {$[0.129]$} & {$[0.118]$} & {$[0.117]$} \\
Dummy for $1977^{*}$ male * Beijing & $0.327^{*}$ & $0.274^{*}$ & $0.284^{*}$ \\
Beijing & {$[0.173]$} & {$[0.165]$} & {$[0.169]$} \\
Game and behavioral controls & 0.263 & 0.249 & 0.270 \\
Individual characteristics controls & {$[0.177]$} & {$[0.167]$} & {$[0.168]$} \\
Observations & $-0.161^{*}$ & $0.786^{* * *}$ & $0.643^{*}$ \\
R-squared & {$[0.085]$} & {$[0.286]$} & {$[0.338]$} \\
\hline \hline & No & Yes & Yes \\
& No & No & 684 \\
& 693 & 688 & 0.216 \\
\hline
\end{tabular}


Table A.3: Estimated results on personality differences

\begin{tabular}{|c|c|c|c|c|c|}
\hline & Ext & Open & Agr & Neur & Cons \\
\hline & \multicolumn{5}{|c|}{ By cohort, gender, and region } \\
\hline \multirow[t]{2}{*}{ Dummy for males } & -0.008 & $0.231^{* *}$ & -0.038 & -0.120 & $0.195^{* *}$ \\
\hline & [0.083] & {$[0.091]$} & {$[0.084]$} & {$[0.105]$} & {$[0.085]$} \\
\hline \multirow[t]{2}{*}{ Dummy for male *Beijing } & -0.114 & $-0.461^{* * *}$ & -0.206 & 0.105 & $-0.333^{* *}$ \\
\hline & {$[0.129]$} & {$[0.139]$} & {$[0.135]$} & {$[0.147]$} & {$[0.136]$} \\
\hline \multirow[t]{2}{*}{ Dummy for 1966} & -0.096 & 0.111 & -0.039 & 0.151 & -0.013 \\
\hline & {$[0.096]$} & {$[0.081]$} & {$[0.079]$} & {$[0.095]$} & {$[0.083]$} \\
\hline \multirow[t]{2}{*}{ Dummy for 1977} & 0.139 & $0.275^{* * *}$ & -0.084 & $0.171^{*}$ & 0.015 \\
\hline & {$[0.101]$} & {$[0.092]$} & {$[0.084]$} & {$[0.094]$} & {$[0.090]$} \\
\hline \multirow[t]{2}{*}{ Dummy for $1966{ }^{*}$ Beijing } & 0.110 & -0.136 & -0.099 & -0.123 & -0.100 \\
\hline & {$[0.134]$} & {$[0.122]$} & {$[0.126]$} & {$[0.143]$} & {$[0.129]$} \\
\hline \multirow[t]{2}{*}{ Dummy for $1977 *$ Beijing } & -0.003 & -0.108 & 0.193 & -0.225 & 0.122 \\
\hline & {$[0.143]$} & {$[0.129]$} & {$[0.128]$} & {$[0.140]$} & {$[0.137]$} \\
\hline \multirow[t]{2}{*}{ Dummy for $1966 *$ male } & $0.283^{* *}$ & 0.033 & -0.061 & -0.162 & -0.107 \\
\hline & {$[0.129]$} & {$[0.130]$} & {$[0.113]$} & {$[0.154]$} & {$[0.124]$} \\
\hline \multirow[t]{2}{*}{ Dummy for $1977 *$ male } & 0.128 & -0.109 & -0.028 & -0.095 & $-0.281^{* *}$ \\
\hline & {$[0.134]$} & {$[0.134]$} & {$[0.119]$} & {$[0.145]$} & {$[0.129]$} \\
\hline \multirow[t]{2}{*}{ Dummy for $1966 *$ male $*$ Beijing } & -0.177 & 0.171 & $0.300 *$ & 0.067 & $0.405^{* *}$ \\
\hline & [0.188] & {$[0.186]$} & {$[0.178]$} & {$[0.207]$} & {$[0.187]$} \\
\hline \multirow[t]{2}{*}{ Dummy for $1977 *$ male $*$ Beijing } & -0.211 & 0.166 & 0.010 & 0.137 & 0.237 \\
\hline & {$[0.196]$} & {$[0.193]$} & {$[0.184]$} & {$[0.202]$} & {$[0.197]$} \\
\hline \multirow[t]{2}{*}{ Beijing } & $0.238^{* * *}$ & $0.325 * * *$ & 0.026 & -0.093 & -0.001 \\
\hline & {$[0.090]$} & {$[0.087]$} & {$[0.096]$} & [0.098] & {$[0.092]$} \\
\hline Observations & 680 & 677 & 677 & 677 & 676 \\
\hline \multirow[t]{2}{*}{ R-squared } & 0.062 & 0.072 & 0.035 & 0.040 & 0.032 \\
\hline & \multicolumn{5}{|c|}{ Aggregated regression: by gender, and region } \\
\hline \multirow[t]{2}{*}{ male } & $0.126^{* *}$ & $0.209^{* * *}$ & -0.068 & $-0.203^{* * *}$ & 0.071 \\
\hline & {$[0.056]$} & {$[0.055]$} & {$[0.047]$} & {$[0.061]$} & {$[0.053]$} \\
\hline \multirow[t]{2}{*}{ beijing } & $0.279^{* * *}$ & $0.252^{* * *}$ & 0.058 & $-0.208^{* * *}$ & 0.010 \\
\hline & {$[0.058]$} & {$[0.052]$} & {$[0.051]$} & {$[0.058]$} & {$[0.055]$} \\
\hline \multirow[t]{2}{*}{$\mathrm{bm}$} & $-0.234^{* * *}$ & $-0.339 * * *$ & -0.098 & $0.169^{* *}$ & -0.116 \\
\hline & {$[0.080]$} & {$[0.077]$} & {$[0.073]$} & {$[0.083]$} & {$[0.078]$} \\
\hline Observations & 680 & 677 & 677 & 677 & 676 \\
\hline R-squared & 0.037 & 0.038 & 0.018 & 0.031 & 0.005 \\
\hline
\end{tabular}

Notes: Authors' own estimation of the personality traits equations. 
Table A.4: The quotas and actual distribution for each cohort-education or cohortemployment cell

\begin{tabular}{|c|c|c|c|c|c|c|}
\hline & \multicolumn{2}{|c|}{1958} & \multicolumn{2}{|c|}{1966} & \multicolumn{2}{|c|}{1977} \\
\hline & Male & Female & Male & Female & Male & Female \\
\hline Education: & \multicolumn{6}{|c|}{ Beijing Quota } \\
\hline Primary or below & 0.00 & 0.02 & 0.02 & 0.00 & 0.00 & 0.02 \\
\hline Junior high & 0.22 & 0.20 & 0.22 & 0.22 & 0.12 & 0.04 \\
\hline Senior high & 0.46 & 0.58 & 0.30 & 0.32 & 0.22 & 0.20 \\
\hline 3-year college/tech school & 0.20 & 0.14 & 0.22 & 0.26 & 0.28 & 0.26 \\
\hline University or above & 0.12 & 0.06 & 0.24 & 0.20 & 0.38 & 0.48 \\
\hline \multicolumn{7}{|l|}{ Employment: } \\
\hline Working & 0.68 & 0.20 & 0.82 & 0.76 & 0.88 & 0.84 \\
\hline Not working & 0.32 & 0.80 & 0.18 & 0.24 & 0.12 & 0.16 \\
\hline Education: & \multicolumn{6}{|c|}{ Beijing Actual } \\
\hline Primary or below & 0.02 & 0.02 & 0.02 & 0.00 & 0.00 & 0.02 \\
\hline Junior high & 0.24 & 0.21 & 0.20 & 0.21 & 0.10 & 0.05 \\
\hline Senior high & 0.41 & 0.51 & 0.25 & 0.32 & 0.19 & 0.16 \\
\hline 3-year college/tech school & 0.24 & 0.18 & 0.30 & 0.30 & 0.26 & 0.25 \\
\hline University or above & 0.07 & 0.09 & 0.23 & 0.18 & 0.45 & 0.52 \\
\hline \multicolumn{7}{|l|}{ Employment: } \\
\hline Working & 0.51 & 0.09 & 0.87 & 0.70 & 0.91 & 0.84 \\
\hline Not working & 0.49 & 0.91 & 0.13 & 0.30 & 0.09 & 0.16 \\
\hline Education: & \multicolumn{6}{|c|}{ Taipei Quota } \\
\hline Primary or below & 0.12 & 0.14 & 0.02 & 0.04 & 0.00 & 0.00 \\
\hline Junior high & 0.24 & 0.22 & 0.14 & 0.12 & 0.10 & 0.04 \\
\hline Senior high & 0.26 & 0.36 & 0.34 & 0.40 & 0.36 & 0.28 \\
\hline 3-year college/tech school & 0.16 & 0.08 & 0.24 & 0.20 & 0.20 & 0.26 \\
\hline University or above & 0.22 & 0.20 & 0.26 & 0.24 & 0.34 & 0.42 \\
\hline \multicolumn{7}{|l|}{ Employment: } \\
\hline Working & 0.78 & 0.42 & 0.90 & 0.68 & 0.90 & 0.76 \\
\hline Not working & 0.22 & 0.58 & 0.10 & 0.32 & 0.10 & 0.24 \\
\hline Education: & \multicolumn{6}{|c|}{ Taipei Actual } \\
\hline Primary or below & 0.05 & 0.15 & 0.02 & 0.03 & 0.00 & 0.00 \\
\hline Junior high & 0.18 & 0.17 & 0.18 & 0.16 & 0.09 & 0.09 \\
\hline Senior high & 0.38 & 0.32 & 0.43 & 0.32 & 0.33 & 0.30 \\
\hline 3-year college/tech school & 0.15 & 0.17 & 0.18 & 0.26 & 0.19 & 0.23 \\
\hline University or above & 0.23 & 0.20 & 0.20 & 0.23 & 0.39 & 0.38 \\
\hline \multicolumn{7}{|l|}{ Employment: } \\
\hline Working & 0.62 & 0.38 & 0.93 & 0.84 & 0.91 & 0.88 \\
\hline Not working & 0.38 & 0.62 & 0.07 & 0.16 & 0.09 & 0.13 \\
\hline
\end{tabular}

Notes: Authors's own calculation from relevant data. 
Table A.5: Sensitivity tests: inclusion of obs. gave wrong answers in the game exercises

\begin{tabular}{|c|c|c|c|c|c|c|}
\hline & \multicolumn{3}{|c|}{ Beijing } & \multicolumn{3}{|c|}{ Taipei } \\
\hline & {$[1]$} & {$[2]$} & {$[3]$} & {$[4]$} & {$[5]$} & {$[6]$} \\
\hline \multirow[t]{2}{*}{ Dummy for males } & $-0.159^{*}$ & $-0.160^{*}$ & $-0.155^{*}$ & .037 & .035 & .031 \\
\hline & {$[0.087]$} & {$[0.087]$} & {$[0.094]$} & {$[0.085]$} & {$[0.086]$} & {$[0.087]$} \\
\hline \multirow[t]{2}{*}{ Dummy for 1966} & -.119 & -.117 & -.11 & -.049 & -.05 & -.091 \\
\hline & {$[0.093]$} & {$[0.093]$} & {$[0.100]$} & {$[0.085]$} & {$[0.085]$} & {$[0.088]$} \\
\hline \multirow[t]{2}{*}{ Dummy for 1977} & -.057 & -.056 & -.048 & .01 & .009 & .013 \\
\hline & {$[0.103]$} & [0.103] & {$[0.112]$} & {$[0.093]$} & {$[0.094]$} & {$[0.095]$} \\
\hline \multirow[t]{2}{*}{ Male*1966 } & $0.299 * *$ & $0.302^{* *}$ & $0.282^{* *}$ & .014 & .015 & .051 \\
\hline & {$[0.124]$} & {$[0.123]$} & {$[0.134]$} & [0.119] & [0.119] & {$[0.122]$} \\
\hline \multirow[t]{2}{*}{ Male*1977 } & $0.212^{*}$ & $0.212^{*}$ & 0.181 & -0.058 & -0.056 & -0.065 \\
\hline & {$[0.120]$} & {$[0.119]$} & {$[0.126]$} & {$[0.117]$} & [0.118] & [0.119] \\
\hline \multirow[t]{2}{*}{ Dummy for wrong answers } & & -0.077 & & & -0.026 & \\
\hline & & {$[0.085]$} & & & {$[0.133]$} & \\
\hline \multirow[t]{2}{*}{ Dummy for round $1=$ round 2} & $0.200^{* *}$ & $0.198^{* *}$ & $0.202^{* *}$ & 0.016 & 0.016 & 0.016 \\
\hline & {$[0.080]$} & {$[0.080]$} & {$[0.085]$} & {$[0.072]$} & {$[0.072]$} & {$[0.073]$} \\
\hline \multirow[t]{2}{*}{ Dummy for round $1<2$} & 0.045 & 0.045 & 0.054 & $0.146^{* *}$ & $0.146^{* *}$ & $0.138^{* *}$ \\
\hline & {$[0.067]$} & {$[0.066]$} & {$[0.073]$} & {$[0.065]$} & {$[0.066]$} & {$[0.067]$} \\
\hline \multirow[t]{2}{*}{ Dummy for round $2=$ round 3} & 0.022 & 0.026 & 0.032 & 0.000 & 0.000 & 0.003 \\
\hline & {$[0.071]$} & {$[0.071]$} & {$[0.077]$} & {$[0.070]$} & {$[0.070]$} & {$[0.072]$} \\
\hline \multirow[t]{2}{*}{ Dummy for round $2<3$} & -0.055 & -0.054 & -0.075 & -0.023 & -0.023 & -0.034 \\
\hline & {$[0.060]$} & {$[0.061]$} & {$[0.063]$} & {$[0.056]$} & {$[0.056]$} & {$[0.057]$} \\
\hline \multirow[t]{2}{*}{ Risk aversion (swithing point) } & -0.001 & -0.001 & $-0.001^{*}$ & $-0.002^{* * *}$ & $-0.002^{* * *}$ & $-0.002^{* * *}$ \\
\hline & {$[0.001]$} & {$[0.001]$} & {$[0.001]$} & {$[0.001]$} & {$[0.001]$} & {$[0.001]$} \\
\hline \multirow[t]{2}{*}{ No. of correct answer in round 2} & $0.035^{* * *}$ & $0.034^{* * *}$ & $0.036^{* * *}$ & $0.043^{* * *}$ & $0.043^{* * *}$ & $0.043^{* * *}$ \\
\hline & {$[0.009]$} & {$[0.009]$} & {$[0.010]$} & {$[0.007]$} & {$[0.007]$} & {$[0.007]$} \\
\hline \multirow[t]{2}{*}{ Raven test score } & 0.017 & 0.016 & 0.015 & $0.041^{* * *}$ & $0.040 * * *$ & $0.040 * * *$ \\
\hline & {$[0.012]$} & {$[0.012]$} & {$[0.013]$} & {$[0.012]$} & {$[0.012]$} & {$[0.013]$} \\
\hline \multirow[t]{2}{*}{ Over-confidence } & 0.032 & 0.031 & 0.035 & 0.033 & 0.033 & 0.036 \\
\hline & {$[0.026]$} & {$[0.027]$} & {$[0.028]$} & {$[0.024]$} & {$[0.024]$} & {$[0.024]$} \\
\hline \multirow[t]{2}{*}{ Dummy for single sex sessions } & -0.047 & -0.050 & -0.059 & $0.105^{* *}$ & $0.106^{* *}$ & $0.113^{* *}$ \\
\hline & {$[0.058]$} & {$[0.058]$} & {$[0.060]$} & {$[0.051]$} & {$[0.051]$} & {$[0.052]$} \\
\hline \multirow[t]{2}{*}{ No. of participants in the session } & -0.005 & -0.005 & -0.005 & 0.008 & 0.009 & $0.009^{*}$ \\
\hline & {$[0.004]$} & {$[0.004]$} & {$[0.004]$} & {$[0.005]$} & {$[0.005]$} & {$[0.005]$} \\
\hline \multirow[t]{2}{*}{ Years of schooling } & 0.007 & 0.007 & 0.007 & -0.010 & -0.010 & -0.010 \\
\hline & {$[0.010]$} & {$[0.010]$} & {$[0.011]$} & {$[0.007]$} & {$[0.007]$} & {$[0.007]$} \\
\hline \multirow[t]{2}{*}{ Mother's years of schooling } & 0.000 & 0.000 & -0.002 & $0.011^{*}$ & 0.011 & $0.013^{*}$ \\
\hline & {$[0.006]$} & {$[0.006]$} & {$[0.007]$} & {$[0.007]$} & {$[0.007]$} & {$[0.007]$} \\
\hline \multirow[t]{2}{*}{ No. of siblings } & -0.018 & -0.018 & -0.015 & -0.013 & -0.013 & -0.014 \\
\hline & {$[0.020]$} & {$[0.020]$} & {$[0.023]$} & {$[0.017]$} & {$[0.017]$} & {$[0.017]$} \\
\hline \multirow[t]{2}{*}{ Constant } & .033 & .042 & .065 & $-0.612^{* *}$ & $-0.614^{* *}$ & $-0.630^{* *}$ \\
\hline & [0.223] & {$[0.222]$} & {$[0.241]$} & {$[0.272]$} & {$[0.272]$} & {$[0.275]$} \\
\hline Observations & 330 & 330 & 300 & 354 & 354 & 340 \\
\hline R-squared & 0.15 & 0.15 & 0.16 & 0.23 & 0.23 & 0.24 \\
\hline
\end{tabular}

Notes: Columns 1 and 4 include all observations; columns 2 and 5 add a dummy variable to indicate individuals who made mistakes in the exercises for the 1st and 2nd rounds of the competition game; columns 3 and 6 exclude individuals who made mistakes in the exercises. 
B Recruitment advertisement

\section{Games for Cash}

Participate in an economics research conducted by Peking University (or) National Taiwan University You will be paid for your participation and decision

\section{You get 75 Yuan (or) T\$510 as long as you} complete the experiment session

The amount of money you will receive will depend on the decisions you make in the experiment.

Average earnings are 230 Yuan (or) T\$1,560

Applicants can only participate once.

Experiments will be held at $x x x$ on date

Experiments last approximately $1 \frac{1}{2}$ hours.

Contact $\mathrm{xxx}$ for details.

Tel No:

Email address: 


\section{Experiment protocols:}

\section{C.1 General Explanations for Participants}

Thanks for coming. There are an outline of this experiment, a detailed instruction of task 1, a participant information, one consent form, and a piece of paper which contains your participant number (ID Number) in this experiment. You will need to present this page together with the ID Number to the cashier at the end of the experiment in order to receive your payment. Do not show this ID Number to anyone or allow it to be visible to anyone during or after this experiment

First, please have a look at the participant information. If you have any questions or concerns about this participant information, please raise your hand. You can sign the consent form if you have no further concerns about the participant information. If you are not comfortable with the information disclosed in the participant information, you can leave immediately. You will still get 75 yuan participation fee if you decide to leave now. But you will not entail to any further payment.

As part of today's experiment, we will be performing 3 tasks and only one task will be paid. The funding for this research has been provided Australian Research Council and Australian National University. At the end of all the tasks I will draw a ball from a bag containing three balls in front of you to determine which task you will be paid for. After finish all experimental tasks and the exist survey, you will be paid by cash for whatever amount you have earned in the selected task. Notice, the different tasks are independent in the sense that the decisions you make in one will have no impact on your outcome in the other.

We are about to begin the first task. Please listen carefully. It is important that you understand the rules of the task properly. If you do not understand, you will not be able to participate effectively. We will explain the task and go through some examples together. There is to be no talking or discussion of the task amongst you. There will be opportunities to ask questions to be sure that you understand how to perform each task. At any time whilst you are waiting during this experiment, please wait at your seat and do not do anything unless instructed by the experimenter. Also do not look at others responses at any time during this experiment. If at any time you decide that you are not happy with the task you have been invited to perform, you can decide not to participate.

After we have completed all the tasks, I would like you to answer some questions about yourself. Please take your time and answer honestly and as accurately as possible. You will not be identified and your survey answers will only be used for this experiment and will only be used by the researcher(s) involved in this project.

If you are ready, then we will proceed. Please turn the page and follow along with the experimenter. 


\section{C.2 Competition Game Instructions}

We are about to begin the 3rd task. This task has 3 rounds, in each round you are required to complete some add-up games. But the earning calculating methods are different from round to round.

Earning from this task depends on your decision, your performance and the performance of the participant you matched with. Please listen carefully.

If this task is chosen to be paid at the end of this experiment. I will draw one ball from a bag containing 3 balls which are exactly the same but with different number on it. The number on the ball we draw out tell us which round we are going to pay.

Notice that because each round has the same chance of been chosen as payment round, you should try your best and treat each round separately to maximize your possible earnings.

First let's have a look at the add-up game.

In add-up game, you need to calculate the sum of 5 random numbers. For example:

\begin{tabular}{|l|l|l|l|l|l|}
\hline 22 & 17 & 83 & 61 & 49 & Answer here \\
\hline
\end{tabular}

In each round, you will be given 5 minutes. You need to work out the sum of the add-up games given and record your answer on the last column. In 5 minutes time, you need to complete add-up games given to you one by one and try your best to complete as many as possible add-up games. You cannot use a calculator (including calculators on you phone). Your performance in each is secrete to others.

There will be two methods to calculate your payoffs in three rounds:

\section{Method of payoff calculation No. 1:}

In five minutes, you will earn 12 yuan for each add-up game you correctly completed. No punishment for wrong answers.

\section{Method of payoff calculation No.2:}

You will be randomly paired with someone in this room. Your earnings depends on your performance and the performance of the participant you paired with. If you correctly complete more add-up games than your partner, you can get 24 yuan for each add-up game you completed in 5 minutes. If your partner and you complete exactly the same number of add-up games in 5 minutes, you will get 12 yuan for each add-up game you correctly completed. If you complete less add-up games than your partner in 5 minutes, you will get nothing.

The following are 2 examples: For the method No.1: if you complete 10 questions correctly, you will earn 1012yuan=120yan

For the method no.2: if you complete 10 questions correctly, your partner complete 9 questions correctly. You will earn 1024yuan=240 yuan

\section{Rules for 1st Round:}

Now I am going to explain the rules for first round.

In the first round, your earning will be calculated according to payoff calculation method No. 1. You have 5 minutes to complete add-up games as many as possible. If this round is selected to be paid, every add-up question you correctly complete within 5 minutes will earn you 12 yuan. There will be no punishment for any wrong answers.

Any Questions? 
Now I will hand out Task 3 round 1 Answer Sheet. Please fill in your ID number first once you get the answer sheet.

\section{Rules for 2nd Round:}

Now I will introduce round two.

In this round, your earning is determined by payoff calculation method No. 2. You have 5 minutes to complete add-up questions as many as possible. You will be randomly paired with someone in this room. Your earnings depends on your performance and the performance of the participant you are paired with. If you correctly complete more add-up questions than your partner, you can get 24 yuan for each add-up game you completed in 5 minutes. If your partner and you complete exactly the same number of questions in 5 minutes, you will get 12 yuan for each question you correctly completed. If you complete less than your partner in 5 minutes, you will get nothing.

Any Questions?

Now I will hand out Task 3 round 2 Answer Sheet. Please fill in your ID number first once you get the answer sheet.

\section{Rules for 3rd Round:}

Now I will introduce round three.

In this round, you will have 5 minutes to solve the sum-up problems. In addition, you have a chance to choose whether to be paid by the payoff calculation method No. 1 or payoff calculation method No. 2. If you choose to be paid by payoff calculation method No. 1 and this round is chosen to be paid, you will earn 12 yuan for each add-up question you correctly completed within the five minutes. No punishment for wrong answers. If you choose to be paid by payoff calculation method No. 2, you will be randomly paired with someone in this room. Your earnings depends on your performance in this round and the performance of your counterpart in Round 2. If you correctly complete more add-up questions than your partner, you can get 24 yuan for each add-up game you completed in 5 minutes. If your partner and you complete exactly the same number of questions in 5 minutes, you will get 12 yuan for each add-up game you correctly completed. If you complete less than your partner in 5 minutes, you will get nothing. Therefore, if this round is chosen to be paid, your earning will be calculated by your choice.

Any Questions?

Now I will hand out Task 3 round 3 Answer Sheet. Please fill in your ID number first once you get the answer sheet.

\section{C.3 Risk Game Instructions}

We are about to begin the 1st task. How much you will be paid in this task depends on your own decision and your luck. No money will be given at this point. All actual payments will be decided at the end of the experiment as to whether this task will be chosen as the one that you will be paid for.

Please listen carefully to the instructions.

In this task, you need to answer 11 questions. For each question, you are given two choices, 
Choice A and Choice B. You can chose one of them. You have to determine whether you would like to be paid by option A or B.

There are two important rules in your choice you need to take notice:

First, you cannot chose Choice B first and then switch in subsequent questions to choice A.

Second, you cannot switch twice from Choice A to Choice B and then back to Choice A.

Therefore, for the 11 questions given to you, you can choose all A, or all B, or switching from A to B once.

Please Note, we are going to pay you one of the 3 tasks only. At the end of all tasks we will determine which task to be paid. If this task is chosen to be paid, we will do the following procedures to determine how much you will be paid.

Particularly, we will choose one person from the group to come up and to pick one ball from this bag, which has 11 exactly the same balls, but each has a different number on it. The number on the ball which is picked by that person will be the question for which we will pay you according to the answer you are given to that question.

For example, if number 10 were chosen, you will be paid according to your choice of the options. Because final payment of option B depends on the result of a flip of coin. We will ask the chosen participants who draw the ball to flip a coin.

If your answer to question number 10 was $\mathrm{A}$, you will be paid 101 yuan. Otherwise, if your answer was B, then we will pay you 441 yuan if coin shows head. We will pay you 0 yuan if you your choice was option B and coin shows tail. Do you have any questions? If you are ready, we will proceed. Please answer the 11 questions in the form in front of you. When you finish, please fold your answer sheet to ensure the anonymity of your answers. Then raise your hand, we will collect the answer sheet from you. 
Figure 5: Risk Game Choices

ID \#:

Task1 Answer Sheet

\begin{tabular}{||c|l|l|c|}
\hline$\#$ & \multicolumn{1}{|c|}{ A } & \multicolumn{1}{c|}{ B } & $\begin{array}{c}\text { Your Choice } \\
\text { (A or B })\end{array}$ \\
\hline 1 & You get 101 yuan & $\begin{array}{l}\text { if coin shows head, you get 135 yuan } \\
\text { if coin shows tail, you get 0 yuan }\end{array}$ & \\
\hline 2 & You get 101 yuan & $\begin{array}{l}\text { if coin shows head, you get 169 yuan } \\
\text { if coin shows tail, you get 0 yuan }\end{array}$ & \\
\hline
\end{tabular}

\begin{tabular}{||c|l|l|l|}
\hline 3 & You get 101 yuan & $\begin{array}{l}\text { if coin shows head, you get } 203 \text { yuan } \\
\text { if coin shows tail, you get } 0 \text { yuan }\end{array}$ & \\
\hline 4 & You get 101 yuan & $\begin{array}{l}\text { if coin shows head, you get } 237 \text { yuan } \\
\text { if coin shows tail, you get } 0 \text { yuan }\end{array}$ & \\
\hline
\end{tabular}
if coin shows tail, you get 0 yuan

\begin{tabular}{|c|l|l|l|}
\hline 5 & You get 101 yuan & $\begin{array}{l}\text { if coin shows head, you get } 271 \text { yuan } \\
\text { if coin shows tail, you get } 0 \text { yuan }\end{array}$ & \\
\hline 6 & You get 101 yuan & $\begin{array}{l}\text { if coin shows head, you get } 305 \text { yuan } \\
\text { if coin shows tail, you get } 0 \text { yuan }\end{array}$ & \\
\hline 7 & You get 101 yuan & $\begin{array}{l}\text { if coin shows head, you get } 339 \text { yuan } \\
\text { if coin shows tail, you get } 0 \text { yuan }\end{array}$ & \\
\hline 8 & You get 101 yuan & $\begin{array}{l}\text { if coin shows head, you get } 373 \text { yuan } \\
\text { if coin shows tail, you get } 0 \text { yuan }\end{array}$ & \\
\hline 9 & You get 101 yuan & $\begin{array}{l}\text { if coin shows head, you get } 407 \text { yuan } \\
\text { if coin shows tail, you get } 0 \text { yuan }\end{array}$ & \\
\hline 10 & You get 101 yuan & $\begin{array}{l}\text { if coin shows head, you get } 441 \text { yuan } \\
\text { if coin shows tail, you get } 0 \text { yuan }\end{array}$ & \\
\hline 11 & You get 101 yuan & $\begin{array}{l}\text { if coin shows head, you get } 475 \text { yuan } \\
\text { if coin shows tail, you get } 0 \text { yuan }\end{array}$ & \\
\hline
\end{tabular}

When you finish, please raise your hand. Please fold this answer sheet and make sure no one can see your answer. We then collect this answer sheet from you

【Please make sure this answer sheet has been folded when collecting】 